\title{
Effects of wave passage on torsional response of symmetric buildings subjected to near-fault pulse-like ground motions
}

\author{
Yenan Cao $^{\text {a }}$, Kristel C. Meza-Fajardo ${ }^{\mathrm{b}}$, George P. Mavroeidis ${ }^{\mathrm{a}, *}$, Apostolos S. \\ Papageorgiou $^{\mathrm{c}}$ \\ ${ }^{a}$ Department of Civil and Environmental Engineering and Earth Sciences, University of Notre Dame, Notre Dame, IN 46556, USA \\ ${ }^{b}$ Department of Civil Engineering, Universidad Nacional Autonoma de Honduras, Tegucigalpa, Honduras \\ ${ }^{c}$ Department of Civil Engineering, University of Patras, Patras 26500, Greece
}

\begin{abstract}
This article investigates the effects of wave passage on the torsional response of elastic buildings in the near-fault region. The model of the soil-foundation-structure system is a symmetric cylinder placed on a rigid circular foundation supported on an elastic halfspace. The idealized model is subjected to obliquely incident plane $\mathrm{SH}$ waves simulating the action of near-fault pulse-like motions. The response of the structure is assessed in terms of the relative twist between the top and the base of the superstructure. A parametric analysis of the maximum relative twist as a function of the input parameters of the seismic excitation and soil-foundation-structure system is performed to identify the parameters that control the torsional response of buildings due to wave passage in the near-fault region. It is shown that the torsional response is most sensitive to a key parameter of the near-fault ground motion referred to as "pulse period". Specifically, large rotations are observed when the pulse period is close to the torsional period of the structure. It is also demonstrated that the wave passage effects are controlled by the wave apparent velocity, rather than the local site conditions. Furthermore, broadband near-fault ground motions from three hypothetical earthquakes of different magnitude are generated, and the torsional responses due to the simplified pulse-like and broadband ground motions are compared against each other. The results show that the simplified pulse model that describes the coherent seismic radiation is able to represent the main features of the near-fault ground motions that cause large torsional response. The maximum relative twist at resonance is found to be $\sim 10^{-3} \mathrm{rad}$, a value that is consistent with the upper bound of rotations in structures reported in the literature.
\end{abstract}

Keywords: wave passage effects; near-fault ground motion; pulse period; wave apparent velocity; torsional response; relative twist; soil-structure interaction

\footnotetext{
* Corresponding author. Tel.: +1-574-631-6245.

E-mail address: g.mavroeidis@nd.edu
} 


\section{Introduction}

During an earthquake, buildings may undergo torsional response in addition to translational response. For buildings with inherent eccentricity (i.e. non-symmetric distribution of masses or loadresisting elements), torsion is induced by the geometrical separation of the centers of mass and stiffness, resulting in coupled lateral-torsional response. On the other hand, spatially varying seismic excitations due to ground motion incoherence and wave passage effects contribute to the torsional response of both symmetric and asymmetric buildings. The ground motion incoherence, which arises from the scattering effect of seismic waves traveling through an inhomogeneous medium, is typically investigated using random-vibration-based procedures, whereas the wave passage effect considers deterministically ground motions that differ in phase from point to point due to the seismic wave front impinging the foundationsoil interface obliquely. Several studies have investigated the effects of wave passage and ground motion incoherence on the torsional response of buildings, but only a few of them are summarized in this section. The interested reader is referred to Anagnostopoulos et al. (2015) for a comprehensive literature review of earthquake-induced torsion in structures.

Newmark (1969) made the first rational attempt to investigate the torsional response of symmetric buildings due to base rotation arising from earthquake wave motions. Luco (1976a,b) presented the complete representation of the torsional steady-state response of a symmetric, elastic structure placed on surface-supported or embedded foundation under the action of obliquely incident plane SH waves accounting for soil-structure interaction effects. It was demonstrated that large displacements associated with torsional response may be generated even for symmetric structures. Luco and Wong (1982) presented the earthquake response of symmetric, elastic structures subjected to SHwave excitation with different angles of incidence and to Rayleigh waves. The results revealed that the response to non-vertically incident waves is significantly different from that obtained on the basis of the usual assumption of vertically incident SH waves.

Luco and Wong (1986) and Luco and Mita (1987) investigated the dynamic response of rigid foundations supported on an elastic halfspace when subjected to a spatially varying ground motion. The results indicated that the spatial randomness of ground motion produces effects similar to the deterministic effects of wave passage, including reduction of the translational components of the response at high frequencies and generation of rocking and torsional response components. Veletsos and Prasad (1989) arrived at a similar conclusion, and further indicated that the kinematic interaction effects due to ground motion incoherence and wave passage may be interrelated. It should be noted that although the studies by Luco and Wong (1986) and Luco and Mita (1987) focused exclusively on the dynamic response of the foundation and did not examine the response of the superstructure, the calculation of the 
torsional response at the foundation level is an essential step for further investigating the dynamic response of the superstructure.

Heredia-Zavoni and Barranco (1996) examined the torsional response of symmetric structural systems subjected to spatially varying ground motions due to loss of coherence, wave passage, and local soil conditions. Torsional effects were found to be significant depending on the aspect ratio of the system, the soil conditions, and the times for the seismic waves to travel across the base of the system, especially for structural systems with fundamental periods close to the predominant period of the ground. De la Llera and Chopra (1994) extracted base torsional excitations, associated with spatially varying ground motions, from translational ground motions recorded at the foundation level of actual buildings. It was shown that accidental torsion increases the building displacements by less than 5\% for systems that are torsionally stiff or have lateral vibration periods longer than $0.5 \mathrm{~s}$, whereas short period (less than $0.5 \mathrm{~s}$ ) and torsionally flexible systems may experience significant increases in response.

Juarez and Aviles (2008) examined the combined torsional effects of structural asymmetry and foundation rotation induced by wave passage in flexibly supported structures. The foundation was considered to be embedded into an elastic halfspace and the earthquake excitation was assumed to be composed of obliquely incident SH waves. An effective eccentricity was defined by matching the equivalent static displacement at the flexible edge of the structure with the peak dynamic displacement. For a low-rise structure, the effects of foundation rotation were found to be detrimental and even more important than those of structural asymmetry, whereas the reverse was observed for a midrise structure. The effects of rocking excitation were found to be insignificant compared to those of the torsional excitation.

Near-fault ground motions are frequently characterized by intense velocity and displacement pulses of relatively long duration, which clearly distinguish them from typical far-field ground motions. Even though intermediate- and long-period structures are particular susceptible to near-fault pulse-like seismic excitations, the attention regarding the effects of such motions on structures has almost exclusively focused on translational vibrations. Only a few studies have touched upon the effects of impulsive motions on the torsional response of buildings due to wave passage or ground motion incoherence. For instance, Heredia-Zavoni and Barranco (1996), although not focusing explicitly on pulse-like seismic excitations, modeled the ground motion input as a narrowband process with a dominant frequency, and concluded that torsional response due to spatially varying ground motions could be significant when the torsional period of the structure is close to the predominant period of the ground motion. This finding implies that near-fault ground motions could potentially induce large torsional response when the period of the pulse-like motion is approximately equal to the torsional period of the structure. In a recent study, Gicev et al. (2015) examined the translation, torsion and wave excitation of a 
two-dimensional building model supported by a nonlinear rectangular, flexible foundation embedded in nonlinear soil. The building model was excited by an earthquake half-sine pulse of a plane SH wave that was intended to model pulse-like motions observed in the near-fault region. Their results showed that the part of energy due to non-translational motion increases rapidly as the angle of incidence (relative to vertical) increases. Gicev et al. (2015) also concluded that the building response becomes spatially more complex as the ratio of building width and wavelength of incident waves increases.

Building upon the methodology and results presented by Meza-Fajardo (2004) (see also MezaFajardo and Papageorgiou, 2004), this article aims to identify the key parameters of the soil-foundationstructure system and ground motion input that control the effects of wave passage on the torsional response of symmetric, elastic buildings under the action of near-fault pulse-like motions. The soilfoundation-structure model proposed by Luco (1976a) is adopted to calculate the torsional response of the buildings, whereas the mathematical model proposed by Mavroeidis and Papageorgiou (2003) is used to describe the coherent component of the near-fault ground motions. The building torsional response is assessed in terms of the relative twist between the top and the base of the superstructure. The characteristics of the transfer function, ground excitation model, and torsional response are investigated through a detailed parametric analysis using realistic physical properties of the soil-foundation-structure system. Finally, broadband near-fault ground motions from hypothetical earthquakes are generated, and the torsional response due to simplified and broadband ground motions are compared to assess the effectiveness of idealized pulse models to estimate accurately the building torsional response due to wave passage in the near-fault region.

\section{Soil-Foundation-Structure System}

\subsection{Model Configuration}

Figure 1 illustrates the soil-foundation-structure model under the action of an obliquely incident plane SH wave proposed by Luco (1976a). This model is adopted in the present study to investigate the effects of wave passage on the torsional response of symmetric, elastic buildings subjected to near-fault pulse-like ground motions. The superstructure is modeled by a uniform elastic bar of height $H$ and radius $a$ with mass moment of inertial about the $z$-axis $I_{\mathrm{b}}$, hysteretic damping factor $\xi$, and fixed-base fundamental frequency in torsion $\omega_{1}$. The foundation is represented by a rigid circular disc with the same

radius as that of the superstructure and mass moment of inertia with respect to the $z$-axis $I_{0}$. The soil is assumed to be an elastic, homogeneous and isotropic halfspace with density $\rho_{\mathrm{s}}$, shear modulus $\mu$, and shear wave velocity $\beta$.

As discussed by Luco (1976a), the frequency response of the soil-foundation-structure system illustrated in Figure 1 can analytically be calculated by considering the ground motion input as an 
obliquely incident plane SH wave of amplitude $u_{\mathrm{g} 0} / 2$ and frequency of steady-state excitation $\omega$, which would lead to a free-field motion of amplitude $u_{\mathrm{g} 0}$ on the ground surface. The plane SH wave is assumed to propagate at an angle $\Theta$ with respect to the $x$ axis (i.e. angle of incidence) and the particle movement is parallel to the $y$ axis, as shown in Figure 1.

It should be pointed out that the soil-foundation-structure model proposed by Luco (1976a) may oversimplify certain aspects of the problem under investigation. For instance, soils and structures subjected to strong ground shaking in the near-fault region may undergo nonlinear response, which cannot be captured by the adopted soil-foundation-structure model that assumes linear response. However, the soil-foundation-structure model proposed by Luco (1976a) is considered to be a suitable model for this study because it facilitates the extensive parametric analysis that is required to identify the input parameters of the seismic excitation and soil-foundation-structure system that control the torsional response of buildings due to wave passage in the near-fault region. It is clear that more realistic models, describing the detailed geometry of the building and taking into account the nonlinear structural response, are required to capture more accurately the behavior of the soil-foundation-structure system for design purposes.

\subsection{Transfer Function}

The torsional response in the frequency domain (also known as transfer function) of the soilfoundation-structure system shown in Figure 1 has been derived analytically by Luco (1976a) and is briefly presented in this section. The average value of the tangential component of displacement $\bar{u}_{\theta}$ of the rigid circular foundation is decomposed into three parts:

$$
\bar{u}_{\theta}=\bar{u}_{\theta}^{i+r}+\bar{u}_{\theta}^{R}+\bar{u}_{\theta}^{S}
$$

where $\bar{u}_{\theta}^{i+r}$ is the average tangential component of the free-field ground motion, $\bar{u}_{\theta}^{R}$ is the motion generated by the foundation twist in the absence of seismic excitation, and $\bar{u}_{\theta}^{S}$ is the average tangential component of motion that needs to be added to the free-field motion when the foundation is kept fixed under the action of seismic excitation. The average tangential component of the free-field motion $\bar{u}_{\theta}^{i+r}$ on the surface of the ground can be obtained by considering the free-field ground motion resulting from the incident and reflected plane SH wave. The mixed boundary value problems corresponding to $\bar{u}_{\theta}^{R}$ and $\bar{u}_{\theta}^{S}$ are reduced to the solution of Fredholm integral equations associated with the numerical evaluation of related functions $\theta_{\mathrm{R}}$ and $\theta_{\mathrm{S}}$. Once the average tangential displacement field $\bar{u}_{\theta}$ is obtained, the average tangential stress field $\bar{\sigma}_{\mathrm{z} \theta}$ may be evaluated by 


$$
\bar{\sigma}_{\mathrm{z} \theta}(r, z)=\frac{1}{2 \pi} \int_{0}^{2 \pi} \sigma_{\mathrm{z} \theta}(r, \theta, z) d \theta=\mu \frac{\partial \bar{u}_{\theta}}{\partial z}
$$

The total torque $T_{s} e^{i \omega t}$ that the rigid foundation exerts on the soil can then be calculated by integrating the average tangential stress field $\bar{\sigma}_{\mathrm{z} \theta}$ along the radius $a$ and by setting $z=0$ :

$$
T_{s} e^{i \omega t}=2 \pi \int_{0}^{a} \bar{\sigma}_{\mathrm{z} \theta}(r, 0) r^{2} d r
$$

By combining Equations (1)-(3) and after lengthy derivations, $T_{s}$ can be expressed by

$$
T_{s}=K_{\mathrm{TT}}\left(a_{0}\right)\left(\alpha_{\mathrm{b}}-\alpha^{*}\right)
$$

where $K_{\mathrm{TT}}\left(a_{0}\right)$ is the torsional impedance function for the foundation calculated as

$$
K_{\mathrm{TT}}\left(a_{0}\right)=16 \mu a^{3} \int_{0}^{1} t \theta_{\mathrm{R}}(t) d t ; \quad a_{0}=a \omega / \beta
$$

$\alpha_{\mathrm{b}}$ is the twist angle of the foundation (also known as base twist), and $a^{*}$ is the input twist that corresponds to the rotation of the rigid foundation under the action of seismic excitation when no external forces are acting on the foundation $\left(T_{s}=0\right)$ :

$$
a^{*}=\left(8 i \mu a^{3} a_{0} \cos \Theta \int_{0}^{1} t \theta_{\mathrm{s}}(t) d t / K_{\mathrm{TT}}\left(a_{0}\right)\right) u_{\mathrm{g} 0} / a
$$

By considering the torque-twist relationship for the superstructure and the coupling of superstructure and soil through the foundation (i.e. equation of motion for the rigid foundation assuming there is no slippage between the soil and the foundation), the base twist $\alpha_{\mathrm{b}}$ can be expressed as

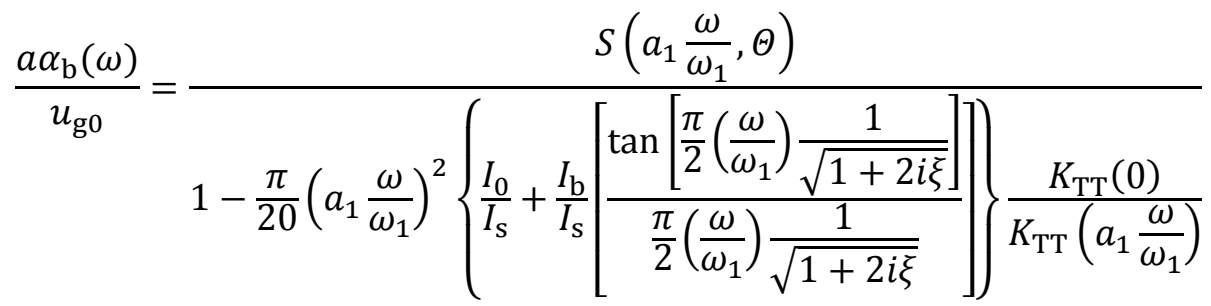


where

$$
\begin{gathered}
S\left(a_{1} \frac{\omega}{\omega_{1}}, \Theta\right)=a a^{*} / u_{\mathrm{g} 0}, \quad a_{1}=a \omega_{1} / \beta=a_{0} \omega_{1} / \omega, \\
I_{\mathrm{S}}=\frac{4 \pi}{15} \rho_{\mathrm{s}} a^{5}, \quad I_{\mathrm{b}}=\frac{1}{2} m_{\mathrm{b}} a^{2}, \quad I_{0}=\frac{1}{2} m_{0} a^{2}
\end{gathered}
$$

with $m_{\mathrm{b}}$ and $m_{0}$ denoting the masses of the superstructure and the foundation, respectively. The twist at the top of the superstructure $\alpha_{\mathrm{t}}$ can then be expressed as a function of the base twist $\alpha_{\mathrm{b}}$ by

$$
\alpha_{\mathrm{t}}(\omega)=\alpha_{\mathrm{b}}(\omega) \sec \left[\frac{\pi}{2}\left(\frac{\omega}{\omega_{1}}\right) \frac{1}{\sqrt{1+2 i \xi}}\right]
$$

whereas the relative twist between the top and the base of the superstructure $\alpha_{\mathrm{r}}$ can be defined as

$$
\alpha_{\mathrm{r}}(\omega)=\alpha_{\mathrm{t}}(\omega)-\alpha_{\mathrm{b}}(\omega)
$$

In summary, the transfer function of the relative twist of the soil-foundation-structure system shown in Figure 1 may be described in terms of the following dimensionless parameters: normalized frequency $\omega / \omega_{1}$, stiffness of the superstructure relative to that of the soil $a_{1}$ (also known as relative stiffness parameter), ratios of moments of inertia $I_{\mathrm{b}} / I_{\mathrm{s}}$ and $I_{0} / I_{\mathrm{s}}$, hysteretic damping factor $\xi$, and angle of incidence $\Theta$ (see also Luco, 1976a).

\subsection{Input Parameters}

Table 1 summarizes the basic characteristics of 40 buildings along with their site conditions considered in this study. This information has been obtained from the empirical evaluation of soilstructure interaction effects conducted by Stewart et al. (1998, 1999). The foundation radius adopted herein is the radius of a circular disc whose area matches the area of the actual foundation (see Stewart et al., 1999). Consistent with findings of previous studies on the evaluation of vibration properties of buildings (e.g. Satake et al., 2003), the torsional fundamental period $T_{1}$ is assumed to be equal to $80 \%$ of the fixed-base translational period of the fundamental mode as that was reported by Stewart et al. (1999).

The relative stiffness parameter $a_{1}$ for each building listed in Table 1 can be calculated by substituting the radius $a$, the torsional fundamental frequency $\omega_{1}=2 \pi / T_{1}$, and the shear wave velocity $\beta$ in Equation (8b). Figure 2a presents the distribution of the calculated relative stiffness parameter $a_{1}$ for 
all buildings considered in this study. This histogram suggests that the majority of buildings have $a_{1}$ values between 0.1 and 1.75, whereas a few stiff buildings (occasionally with large radius) on soft soil conditions (i.e. small shear wave velocity) are characterized by values of $a_{1}$ between 2.0 and 5.5.

The ratios of moments of inertia, $I_{\mathrm{b}} / I_{\mathrm{s}}$ and $I_{0} / I_{\mathrm{s}}$, can be calculated by using Equation $(8 \mathrm{c}-\mathrm{e})$ in conjunction with the foundation radius $a$ and typical values of $\rho_{\mathrm{s}}, m_{\mathrm{b}}$ and $m_{0}$. For instance, the soil density $\rho_{\mathrm{s}}$ ranges from $1.5-2.4 \mathrm{Mg} / \mathrm{m}^{3}$ depending on the type of soil (Holtz et al., 2011). The mass of the superstructure $m_{\mathrm{b}}$ for typical residential and office buildings may be calculated as follows:

$$
m_{\mathrm{b}}=\rho_{\mathrm{b}} H A
$$

with

$$
\rho_{\mathrm{b}} \approx \frac{q}{g h_{0}}
$$

where $\rho_{\mathrm{b}}$ is the mass density of the superstructure, $H$ and $A=\pi a^{2}$ are the height and floor area of the building, $h_{0}$ is the interstory height, and $q$ is the gravity load consisting of dead and live loads. Once the mass of the superstructure $m_{\mathrm{b}}$ has been calculated using Equation (11), the mass of the foundation $m_{0}$ can be estimated for typical buildings (e.g. Veletsos and Meek, 1974; Juarez and Aviles, 2008; Zhang and Tang, 2008) as:

$$
m_{0} \approx(0.05-0.35) m_{\mathrm{b}}
$$

The interstory height for residential and office buildings is about $3.5 \mathrm{~m}(11.5 \mathrm{ft})$. Average gross dead loads are 4.8-7.2 kN/m² $\left(100-150 \mathrm{lb} / \mathrm{ft}^{2}\right)$ for reinforced concrete buildings and 2.9-3.8 kN/m² $(60$ $80 \mathrm{lb} / \mathrm{ft}^{2}$ ) for steel framed buildings (e.g. Saouma, 2004), whereas the minimum uniformly distributed live loads typically vary between $1.9-4.8 \mathrm{kN} / \mathrm{m}^{2}\left(40-100 \mathrm{lb} / \mathrm{ft}^{2}\right)$ depending on the occupancy characterization of the building (ASCE, 2010; CTBUH, 1995). By considering the aforementioned values of interstory height, dead load and live load, the mass density of the superstructure $\rho_{\mathrm{b}}$ of Equation (11b) is estimated in the range of $150-350 \mathrm{~kg} / \mathrm{m}^{3}$. Typical values of the mass density of the entire building block (including the foundation system) reported in the literature are between $250-350 \mathrm{~kg} / \mathrm{m}^{3}$ (e.g. Tsogka and Wirgin, 2003; Kham et al., 2006). It should be noted though that the mass density of the entire building is typically greater than $\rho_{\mathrm{b}}$.

Representative values of $I_{\mathrm{b}} / I_{\mathrm{s}}$ can be calculated by combining Equations $(8 \mathrm{c}, \mathrm{d})$ and (11) and by setting $\rho_{\mathrm{s}}$ and $\rho_{\mathrm{b}}$ equal to their average values (i.e. $\rho_{\mathrm{s}}=1.95 \mathrm{Mg} / \mathrm{m}^{3}, \rho_{\mathrm{b}}=250 \mathrm{~kg} / \mathrm{m}^{3}$ ). Figure $2 \mathrm{~b}$ illustrates the distribution of $I_{\mathrm{b}} / I_{\mathrm{s}}$ for all 40 buildings listed in Table 1 with the majority of these values 
being between 0.1 and 0.7 . Buildings with $I_{\mathrm{b}} / I_{\mathrm{s}}>0.7$ are typically characterized by large $H / a$ ratios. Similarly, $I_{0} / I_{\mathrm{S}}$ can be computed by combining Equations (8c,e), (11) and (12). Provided that the superstructure and the foundation have the same radius $a$, the ratio of $I_{0} / I_{\mathrm{S}}$ can alternatively be calculated by multiplying $I_{\mathrm{b}} / I_{\mathrm{s}}$ with the foundation-to-superstructure mass ratio $m_{0} / m_{\mathrm{b}}$, which has been shown to vary between 0.05 and 0.35 according to Equation (12).

To obtain a complete set of structural input parameters, the hysteretic damping factor $\xi$ is approximated by the equivalent viscous damping ratio. In general, viscous damping ratios are spread over a relatively wide range (0.5-9.0\%) depending on the material (steel vs. reinforced concrete) and height of the building (e.g. Satake et al., 2003; PEER/ATC, 2010; Bernal et al., 2015). Viscous damping ratios are also sensitive to the system identification algorithm utilized in the analysis, as well as the type and level of excitation used as an input (i.e. earthquake-, wind- or forced-induced vibration). For buildings subjected to earthquake loads, values of $\xi=3.0 \%$ and $5 \%$ are typically assumed for steel and concrete buildings, respectively. For very tall steel buildings, even smaller values of $\xi$ may be considered (e.g. Bernal et al., 2015).

For the parametric analyses presented in this study, the soil density $\rho_{\mathrm{S}}$, the mass density of the superstructure $\rho_{\mathrm{b}}$, the foundation-to-superstructure mass ratio $m_{0} / m_{\mathrm{b}}$, and the hysteretic damping factor $\xi$ are set equal to their average values (i.e. $\rho_{\mathrm{s}}=1.95 \mathrm{Mg} / \mathrm{m}^{3}, \rho_{\mathrm{b}}=250 \mathrm{~kg} / \mathrm{m}^{3}, m_{0} / m_{\mathrm{b}}=0.2$, and $\xi=$ 4\%). In Section 4, the effect of these four parameters on the torsional response of buildings due to wave passage in the near-fault region will further be investigated and shown to be insignificant.

\subsection{Parametric Analysis}

This section presents a parametric analysis of the transfer function of the relative twist between the top and the base of the superstructure $\alpha_{\mathrm{r}}$, expressed by Equation (10), for the soil-foundation-structure system shown in Figure 1 subjected to an obliquely incident plane SH wave. In an effort to model realistic configurations of buildings and soil conditions, input parameters $a_{1}$ and $I_{\mathrm{b}} / I_{\mathrm{s}}$ are selected to be consistent with the histogram distributions presented in Figure 2. Namely, the selected values of the relative stiffness parameter $a_{1}$ are $0.2,0.7,1.2,2.2,3.2$ and 5.0, whereas the values of the ratio of moments of inertia $I_{\mathrm{b}} / I_{\mathrm{s}}$ are $0.1,0.8$ and 1.7. Following the discussion in Section 2.3, the hysteretic damping factor $\xi$ and the foundation-to-structure mass ratio $m_{0} / m_{\mathrm{b}}$ are set equal to $4 \%$ and 0.2 , respectively. Finally, three angles of incidence $\Theta$ are considered: $0^{\circ}, 40^{\circ}$ and $80^{\circ}$.

The parametric analysis results in Figure 3 are presented in terms of the modulus of normalized relative twist $\left|a \alpha_{\mathrm{r}} / u_{\mathrm{g} 0}\right|$ and the normalized frequency $\omega / \omega_{1}$ for distinct values of $a_{1}, I_{\mathrm{b}} / I_{\mathrm{s}}$, and $\Theta$. Parameter $\left|a \alpha_{\mathrm{r}} / u_{\mathrm{g} 0}\right|$ may be interpreted as the ratio of the tangential component of relative motion on the 
perimeter associated with the torsional response generated by obliquely incident seismic waves over the amplitude of the free-field motion. For the vast majority of cases, the twist at the top has much larger amplitude than the twist at the base, and therefore the relative twist is principally dominated by the twist at the top. Only for cases characterized by large $a_{1}$ and $I_{\mathrm{b}} / I_{\mathrm{s}}$ values (e.g. $a_{1}>3$ and $I_{\mathrm{b}} / I_{\mathrm{s}}>1$ ), the base twist is as large as the top twist and thus the amplitude of the relative twist is small. In the remainder of this article, the relative twist between the top and the base of the superstructure $\alpha_{\mathrm{r}}$ (i.e. termed "relative twist" for simplicity) is designated as the single response quantity of interest. In Section 4.1, it will be shown that $\alpha_{\mathrm{r}}$ is indeed a suitable response quantity for investigating the effects of wave passage on the torsional response of buildings subjected to near-fault pulse-like motions.

As shown in Figure 3, the transfer function of the relative twist of the superstructure, expressed in normalized form by $\left|a \alpha_{\mathrm{r}} / u_{\mathrm{g} 0}\right|$, is dependent on $a_{1}, I_{\mathrm{b}} / I_{\mathrm{s}}, \Theta$, and $\omega / \omega_{1}$. The relative stiffness parameter $a_{1}$ has a significant effect on the transfer function of the relative twist. For very flexible buildings or very stiff soils (e.g. $a_{1}=0.2$ ) and for very stiff buildings or very soft soils (e.g. $a_{1}=5.0$ ), the amplitude of the tangential component of relative motion is small and generally less than the amplitude of the free-field motion. For $a_{1}=1.2$, the amplification factor $\left|a \alpha_{\mathrm{r}} / u_{\mathrm{g} 0}\right|$ could reach peak values of up to $\sim 8$ depending on the particular values of $I_{\mathrm{b}} / I_{\mathrm{s}}$ and $\Theta$. Furthermore, it should be noted that, as $a_{1}$ increases from 0.2 to 5.0 , the resonance frequency of the first peak response tends to decrease, especially for larger values of $I_{\mathrm{b}} / I_{\mathrm{s}}$.

Inspection of Figure 3 also reveals that the angle of incidence $\Theta$ largely affects the transfer function of the relative twist. For smaller values of $a_{1}$ (e.g. $\left.a_{1}<2.5\right)$, the maximum response occurs for horizontal incidence $(\Theta=0)$ and decreases monotonically to zero as $\Theta$ increases to $90^{\circ}$ regardless of the $I_{\mathrm{b}} / I_{\mathrm{s}}$ value. For larger values of $a_{1}$ (e.g. $a_{1}>2.5$ ), the effect of $\Theta$ on the maximum response is more complex and depends on the value of $I_{\mathrm{b}} / I_{\mathrm{s}}$. Finally, Figure 3 illustrates that larger values of $I_{\mathrm{b}} / I_{\mathrm{s}}$, tend to reduce the amplitude of the first peak response and shift the corresponding resonance frequency of the soil-foundation-structure system to values smaller than the fixed-base fundamental frequency in torsion $\omega_{1}$.

Figure 4a shows the variation of the amplitude of the first peak response with respect to $a_{1}$ and $\Theta$ for characteristic values of $I_{\mathrm{b}} / I_{\mathrm{s}}$. The maximum amplitude is obtained for $I_{\mathrm{b}} / I_{\mathrm{s}}=0.1$ and $a_{1} \approx 1.5$ under the action of horizontal incidence $(\Theta=0)$. Figures $4 \mathrm{~b}$ and $4 \mathrm{c}$ illustrate cross sections of Figure $4 \mathrm{a}$ for $a_{1}=1.5$ and 4.5, whereas Figures $4 \mathrm{~d}$ and $4 \mathrm{e}$ illustrate cross sections of Figure $4 \mathrm{a}$ for $\Theta=40^{\circ}$ and $80^{\circ}$. As shown in Figures $4 \mathrm{~d}$ and $4 \mathrm{e}$, the amplitude of the first peak response varies linearly with $a_{1}$ for $a_{1}<0.8$ and is not dependent on the variation of $I_{\mathrm{b}} / I_{\mathrm{s}}$. 


\section{Near-Fault Ground Motions}

In this study, the soil-foundation-structure system shown in Figure 1 is subjected to near-fault pulse-like ground motions which are assumed to arise from the superposition of incident non-vertical plane SH waves and their total reflections on the free surface. Near-fault seismic ground motions are frequently characterized by intense velocity and displacement pulses of relatively long duration that clearly distinguish them from typical far-field ground motions. The existence of pulse-like motions in near-fault records primarily depends on the relative position of the station that recorded the motion with respect to the direction of propagation of rupture on the causative fault plane and on the magnitude and direction of slip on that segment of the fault that is located in the vicinity of the station. Whenever these ground motion pulses do occur, they are typically caused by the forward directivity and/or permanent translation (fling) effects (e.g. Mavroeidis and Papageorgiou, 2003) and are strongly correlated with large slip on the fault plane locally driven by high stress drop (e.g. Mavroeidis and Papageorgiou, 2010).

\subsection{Mathematical Model}

For evaluating the effects of wave passage on the torsional response of buildings subjected to near-fault pulse-like motions, the mathematical model proposed by Mavroeidis and Papageorgiou (2003) is adopted to describe the coherent component of the seismic excitation input in the near-fault region. The mathematical formulation proposed by Mavroeidis and Papageorgiou (2003) for the representation of the near-fault velocity pulses is the product of a harmonic oscillation and a bell-shaped function, that is:

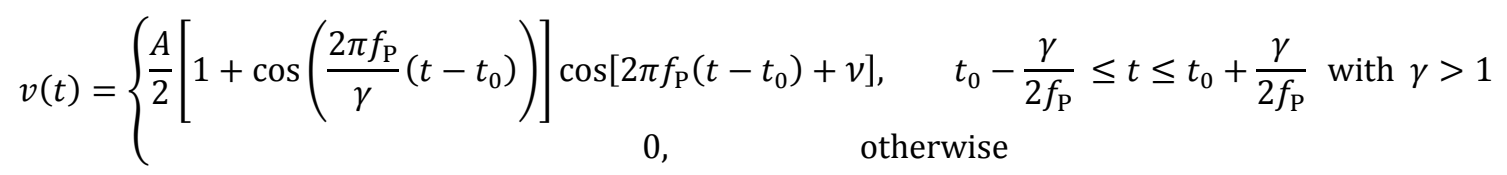

where $A$ controls the amplitude of the signal, $f_{\mathrm{P}}$ is the prevailing frequency of the signal, $v$ is the phase of the amplitude-modulated harmonic, $\gamma$ is a parameter that defines the oscillatory character of the signal, and $t_{0}$ specifies the epoch of the envelope's peak. The pulse period $T_{\mathrm{P}}$ is defined as the inverse of the prevailing frequency $f_{\mathrm{P}}$, thus providing an "objective" assessment of this important parameter:

$$
T_{\mathrm{P}}=\frac{1}{f_{\mathrm{P}}}
$$

The model input parameters have a clear physical meaning as they coincide with the key features that determine the waveform characteristics of the near-fault pulses (i.e. amplitude, duration, phase and 
number of half cycles). In addition, the closed-form expression of Equation (13) has the potential to facilitate the parametric investigation of the dynamic response of structural models (similar to the one shown in Figure 1) to variations of the ground motion input parameters (i.e. $A, T_{\mathrm{P}}, \gamma$, and $v$ ) that affect near-fault pulse-like motions.

\subsection{Input Parameters}

In previous studies, the scaling characteristics of the model input parameters were investigated using a large set of actual near-fault ground motion records affected by forward directivity, and simple empirical relationships were proposed (Mavroeidis and Papageorgiou, 2003; Halldorsson et al., 2011; Cork et al., 2016). By performing least-squares analysis, Mavroeidis and Papageorgiou (2003) (see also Cork et al., 2016) obtained the following relationship between the pulse period $T_{\mathrm{P}}$ and the earthquake magnitude $M_{\mathrm{W}}$ with the requirement to satisfy the self-similarity condition:

$$
\log T_{\mathrm{P}}=-2.9+0.5 M_{\mathrm{W}}
$$

The amplitude of the near-fault velocity records appears to be a fairly stable parameter. A value of $100 \mathrm{~cm} / \mathrm{s}$ effectively represents peak ground velocities within a few kilometers from the causative fault regardless of the earthquake magnitude (Mavroeidis and Papageorgiou 2003). This observation is in good agreement with the typical slip velocity value of $100 \mathrm{~cm} / \mathrm{s}$ frequently considered by seismologists. As indicated by Mavroeidis et al. (2004), there are solid physical reasons that explain the stability of the velocity amplitude close to the fault. More recently, Halldorsson et al. (2011) and Cork et al. (2016) proposed attenuation relationships for peak ground velocity (PGV) with rupture distance $R$. Finally, parameter $\gamma$ varies from a value slightly larger than 1 up to a maximum value of 3 , whereas the phase angle $v$ varies from 0 to $360^{\circ}$. Halldorsson et al. (2011) provided the probability density functions for $\gamma$ and $v$, assuming that these two parameters are normally distributed.

In this study, $T_{\mathrm{P}}$ ranges from 0.5 to $10 \mathrm{~s}$ with an increment of $0.05 \mathrm{~s}$. According to Equation (15), this range of values for $T_{\mathrm{P}}$ corresponds to earthquake magnitudes $M_{\mathrm{W}}$ between 5.2 and 7.8. Parameter $A$ is fixed to $100 \mathrm{~cm} / \mathrm{s}$ based on the recommendation made by Mavroeidis and Papageorgiou (2003) and Mavroeidis et al. (2004) for sites located within a few kilometers from the causative fault. The effect of $\gamma$ is taken into account by considering four characteristic values: 1.0, 1.5, 2.0, and 3.0. Finally, parameter $v$ is set equal to $90^{\circ}$ to ensure that the displacement offset vanishes for all generated motions in agreement with the waveform characteristics of pure forward directivity motions. It should also be pointed out that the variation of $v$ has little effect on the Fourier amplitude spectrum of the ground velocity (see Mavroeidis and Papageorgiou, 2003), a quantity used in Section 4 to investigate the effects of wave 
passage on the torsional response of symmetric, elastic buildings under the action of near-fault pulse-like motions. Mavroeidis et al. (2004) have also shown that the effect of $v$ on the response of elastic and inelastic single-degree-of-freedom (SDOF) systems is insignificant.

\subsection{Parametric Analysis}

Mavroeidis and Papageorgiou (2003) derived a closed-form expression for the Fourier transform $V(\omega)$ of the velocity signal provided by Equation (13) as a function of $A, T_{\mathrm{P}}, \gamma$, and $v$. The Fourier transform $D(\omega)$ of the corresponding displacement signal can readily be derived by the following equation:

$$
D(\omega)=\frac{V(\omega)}{\mathrm{i} \omega}
$$

Figure 5 illustrates the variation of the normalized Fourier amplitude of displacement $|D(\omega)| \omega_{\mathrm{P}}^{2} /$ $A$ as a function of the normalized frequency $\omega / \omega_{\mathrm{P}}$ (where $\omega_{\mathrm{P}}=2 \pi f_{\mathrm{P}}$ ) for characteristic values of $\gamma$. Inspection of this figure reveals that the Fourier amplitude spectrum of displacement is a relatively narrowband spectrum with its peak amplitude depending on $\gamma, A$ and $\omega_{\mathrm{P}}$. For constant values of $\omega_{\mathrm{P}}$ and $A$, the effect of $\gamma$ on the Fourier amplitude spectrum depends on the frequency range of interest. For $0.5 \leq \omega / \omega_{\mathrm{p}} \leq 1.5$, the Fourier amplitude increases with $\gamma$, while this trend is reversed for $\omega / \omega_{\mathrm{p}} \geq 1.5$. Overall the peak amplitude of the spectrum is increased by a factor of $\sim 2$ as $\gamma$ increases from 1 to 3 . Also for a constant value of $\omega_{\mathrm{P}}$, a larger value of $\gamma$ gives rise to a narrower bandwidth, with the frequency of the peak amplitude being closer to the prevailing frequency $\omega_{\mathrm{P}}$ of the pulse. In addition, as was explained in Section 3.2, parameter $A$ that scales the spectral ordinates is a stable parameter within a few kilometers from the causative fault. On the other hand, $\omega_{\mathrm{P}}$ (or equivalently $T_{\mathrm{P}}=2 \pi / \omega_{\mathrm{P}}$ ) turns out to be the most important parameter. Note that the displacement Fourier amplitude spectrum is normalized with respect to $\omega_{\mathrm{P}}^{2}$, meaning that the Fourier amplitude increases quadratically with $T_{\mathrm{P}}$. For the range of pulse periods considered in this study $\left(T_{\mathrm{P}}=0.5-10 \mathrm{~s}\right)$, the Fourier amplitude would vary by a factor of 400 . Hence, it is reasonable to conclude that, although $\gamma$ and $A$ contribute to the variability of the Fourier amplitude spectrum of displacement, the dominant parameter is the pulse period $T_{\mathrm{P}}$.

\section{Torsional Response due to Simplified Near-Fault Pulse-Like Ground Motions}

In this section, a detailed investigation is performed to identify the key parameters of the soilfoundation-structure system and ground motion input that control the effects of wave passage on the torsional response of symmetric, elastic buildings under the action of simplified near-fault pulse-like 
motions. The torsional response of the soil-foundation-structure system in the frequency domain is first calculated by multiplying the transfer function of the relative twist $\alpha_{\mathrm{r}}(\omega)$ of the superstructure subjected to an obliquely incident plane SH wave with the Fourier transform $D(\omega)$ of the simplified ground displacement. The transfer function $\alpha_{\mathrm{r}}(\omega)$ can be calculated by combing Equations (10), (9) and (7) for $u_{\mathrm{g} 0}=1$, whereas $D(\omega)$ can be computed from Equation (16). The relative twist of the superstructure in the time domain is then obtained by applying the inverse Fast Fourier transform. The response quantity of interest is the maximum relative twist expressed in radians.

As was mentioned in Section 2.3, the soil density $\rho_{\mathrm{s}}$, the mass density of the superstructure $\rho_{\mathrm{b}}$, the foundation-to-superstructure mass ratio $m_{0} / m_{\mathrm{b}}$, and the hysteretic damping factor $\xi$ are set equal to their average values (i.e. $\rho_{\mathrm{s}}=1.95 \mathrm{Mg} / \mathrm{m}^{3}, \rho_{\mathrm{b}}=250 \mathrm{~kg} / \mathrm{m}^{3}, m_{0} / m_{\mathrm{b}}=0.2$, and $\xi=4 \%$ ). By varying these parameters over their potential range of values presented in Section 2.3 (i.e. $\rho_{\mathrm{s}} \in[1.5,2.4] \mathrm{Mg} / \mathrm{m}^{3}$, $\rho_{\mathrm{b}} \in[150,350] \mathrm{kg} / \mathrm{m}^{3}, m_{0} / m_{\mathrm{b}} \in[0.05,0.35]$, and $\left.\xi \in[3 \%, 5 \%]\right)$, the building torsional response due to wave passage changes by less than $20 \%$ as compared to the torsional response computed based on the average values of these parameters, and thus their overall effect on the torsional response is considered to be relatively small.

\subsection{Effect of Ground Motion Parameters}

Three buildings with short, intermediate and long periods are selected from Table 1 to examine the effect of ground motion parameters on torsional response: Building A10 (3 stories, $H=14.4 \mathrm{~m}$, $a=22.9 \mathrm{~m}, T_{1}=0.22 \mathrm{~s}$ and $\beta=234.1 \mathrm{~m} / \mathrm{s}$ ), Building A36 (6 stories, $H=23.1 \mathrm{~m}, a=15.2 \mathrm{~m}$, $T_{1}=0.86 \mathrm{~s}$ and $\beta=362.1 \mathrm{~m} / \mathrm{s}$ ), and Building A28 (19 stories, $H=95.8 \mathrm{~m}, a=28.0 \mathrm{~m}, T_{1}=2.76 \mathrm{~s}$ and $\beta=298.7 \mathrm{~m} / \mathrm{s}$ ). Figure 6 presents the maximum relative twist of the three buildings as a function of the normalized period $T_{\mathrm{P}} / T_{1}$ for different values of $\gamma$ and $\Theta$. Since the $T_{\mathrm{P}}$ values considered in this study range from 0.5 to $10 \mathrm{~s}$ (corresponding to $M_{\mathrm{W}}$ 5.2-7.8), the effective range of $T_{\mathrm{P}} / T_{1}$ over which Figure 6 is plotted differs for each of the three buildings because of their distinct torsional periods $T_{1}$. With reference to Figure 6, the following observations are made:

- The global peak of the maximum relative twist is attained when $T_{\mathrm{P}} / \mathrm{T}_{1}$ approaches a value slightly larger than one (see Buildings A28 and A36), indicating that resonance occurs when the pulse period approaches the torsional period of the building. This is in agreement with observations reported previously by Mavroeidis et al. (2004) and Hubbard and Mavroeidis (2011) with regard to the resonance response of SDOF systems subjected to near-fault pulse-like excitations. When $T_{\mathrm{P}} / \mathrm{T}_{1}$ becomes equal to $\sim 0.6$ (see Building A28), a local peak amplification is observed associated with the excitation of the second mode which is evident in Figure 3. As shown in Figure 6, the maximum 
relative twist that corresponds to the first mode is greater than the one of the second mode. This can be attributed to the fact that (a) the Fourier amplitude spectrum of the ground displacement decays quadratically as $\omega_{\mathrm{P}}$ increases (or equivalently $T_{\mathrm{P}}$ decreases) (see Figure 5), and (b) the amplitude of the transfer function of the relative twist for the first mode is typically greater than that of the second mode (see Figure 3). Finally, Building A10 is not subjected to resonance response due to the range of $T_{\mathrm{P}} / \mathrm{T}_{1}$ values considered in this study, and thus the response tends to be significantly smaller than the response of Buildings A28 and A36.

- As $\gamma$ increases from 1 to 3, the global peak of the maximum relative twist (resonance response) increases by a factor of $\sim 2$ and the shape of the response curve changes gradually from "flattened" to "peaked". It is also worth mentioning that for $T_{\mathrm{P}} / T_{1}>1.5$, the maximum relative twist decreases as $\gamma$ increases from 1 to 3 . These observations are consistent with the observed influence of $\gamma$ on the Fourier amplitude spectrum of the ground displacement (see Section 3.3 and Figure 5).

- Comparison of Figures $6 \mathrm{a}$ and $6 \mathrm{~b}$ indicates that the maximum relative twist decreases significantly as $\Theta$ increases from $40^{\circ}$ to $80^{\circ}$. This observation is consistent with the effect of $\Theta$ on the transfer function of the relative twist for $a_{1}<2.5$ discussed previously (see Section 2.4 and Figure 3; for reference, $a_{1}$ values for Buildings A10, A36, and A28 are less than 2.5).

- The maximum relative twists for the short-, intermediate- and long-period buildings shown in Figure 6a or Figure $6 \mathrm{~b}$ cannot be compared to one another in a meaningful way, even for fixed values of $\gamma$ and $\Theta$. In addition to $\gamma$ and $\Theta$, the maximum relative twist depends on various parameters, including $a, I_{\mathrm{b}} / I_{\mathrm{S}}, a_{1}$ (which also incorporates the effect of $\beta$ ), as well as $\omega_{\mathrm{P}}$ (or equivalently $T_{\mathrm{P}}$ ) and $\omega_{1}$ (or equivalently $T_{1}$ ). Finally, it should be reiterated that Figure 6 does not incorporate the effect of $A$ on torsional response since this ground motion parameter was fixed to $100 \mathrm{~cm} / \mathrm{s}$ for reasons that are outlined in Section 3.2. Nevertheless, the effect of $A$ on the maximum relative twist can be taken into account by considering the attenuation relationships for peak ground velocity (PGV) with rupture distance $R$ proposed by Halldorsson et al. (2011) or Cork et al. (2016) and by scaling the ordinates of the response curves accordingly.

Figure 7a presents the same parametric analysis as the one shown in Figure 6a for Building A28 with the exception that the response quantity of interest is the overall maximum relative twist between any point along the height of the building and its base. Comparison of Figures 7a and 6a for Building A28 indicates that the maximum relative twist between the top and the base of the building is identical to the computed overall maximum relative twist between any point along the height of the building and its base with the exception of points lying on the tail of the response curve for $T_{\mathrm{P}} / T_{1} \leq 0.4$ (i.e. circled by dashed line in Figure 7a). This can be attributed to higher mode effects as shown in Figure $7 \mathrm{~b}$ where the variation 
of the maximum relative twist along the height of the building is plotted for $T_{\mathrm{P}} / T_{1}=0.2,1.0$ and 1.8. For $T_{\mathrm{P}} / T_{1}=1.0$ and 1.8 , the maximum relative twist along height increases monotonically as $z / H$ increases from 0 to 1 indicating the dominant effect of the first mode and that the overall maximum relative twist along height is identical to the maximum relative twist between top and base. However, in the case of $T_{\mathrm{P}} / T_{1}=0.2$, the maximum relative twist between top and base is about $20 \%$ smaller than the overall maximum relative twist along height, which occurs at $\sim 30 \%-40 \%$ of the building height depending on the value of $\gamma$. It should parenthetically be noted that for Buildings A10 and A36, the maximum relative twist between top and base is identical to the overall maximum relative twist along height for all values of $T_{\mathrm{P}} / T_{1}$ considered in the analysis. Therefore, although the maximum relative twist between top and base would slightly underestimate the overall maximum relative twist along height for small values of $T_{\mathrm{P}} / T_{1}$ due to higher mode effects, it is deemed an appropriate quantity for representing the largest torsional response for the vast majority of cases and certainly for $T_{\mathrm{P}} / T_{1} \approx 1$ where the global peak of the maximum torsional response is attained.

\subsection{Physical Constraints on Angle of Incidence}

As was discussed in Sections 2.4 and 4.1, the transfer function and thus the maximum relative twist depend on the angle of incidence $\Theta$. In reality, the impinging directions of the traveling seismic waves are considerably close to vertical. The primary reason is that soils are layered with shear wave velocities increasing with depth and therefore the refraction of waves at the layer interfaces cause the waves to travel in a more vertical direction as they approach the ground surface (e.g. O'Rourke et al., 1982).

The angle of incidence $\Theta$ of a plane SH wave and the shear wave velocity $\beta$ at the top soil layer are related through the following equation:

$$
c_{\mathrm{H}}=\frac{\beta}{\cos \Theta}
$$

where $c_{\mathrm{H}}$ is the wave apparent horizontal velocity. Previous studies published in the literature have estimated the range of $c_{\mathrm{H}}$ values of body waves in the near-fault region using empirical or numerical approaches. For instance, O'Rourke et al. (1982) approximated $c_{\mathrm{H}}$ at a particular site based on the three acceleration components of ground motion and the material properties of the top layer. The method was applied to several sites that recorded the 1971 San Fernando and 1979 Imperial Valley earthquakes, and the median $c_{\mathrm{H}}$ values reported by O'Rourke et al. (1982) for the two earthquakes were 2.1 and $3.8 \mathrm{~km} / \mathrm{s}$, respectively. Through numerical simulations of ground motion in the near-fault region, Bouchon and Aki 
(1982) concluded that $c_{\mathrm{H}}$ is controlled by the rupture velocity on the fault plane or the shear wave velocity of the basement rock with values ranging between 2.2 and $3.5 \mathrm{~km} / \mathrm{s}$. The numerical values of $c_{\mathrm{H}}$ computed by Luco and Sotiropoulos (1980) for different epicentral distances and source depths using a simple model of the seismic source and propagation medium are also in good agreement with the $c_{\mathrm{H}}$ values reported by O’Rourke et al. (1982) and Bouchon and Aki (1982).

Three representative values of $c_{\mathrm{H}}$ (i.e. $2.0,2.9$ and $3.8 \mathrm{~km} / \mathrm{s}$ ) and four representative values of $\beta$ (i.e. 1130, 560, 270 and $170 \mathrm{~m} / \mathrm{s}$ ) corresponding to the National Earthquake Hazards Reduction Program (NEHRP) Site Classes B, C, D and E (BSSC, 2004) are selected for the parametric analysis presented in Sections 4.2 and 4.3. By substituting these representative $c_{\mathrm{H}}$ and $\beta$ values into Equation (17), the angle of incidence $\Theta$ is estimated to vary between $55.6^{\circ}$ and $87.4^{\circ}$, suggesting that the impinging directions of the traveling seismic waves are mostly close to vertical. Note that the adopted values of $\beta$ aim to examine the effect of different soil types on torsional response and do not necessarily reflect the site conditions of any particular building listed in Table 1.

Figure 8 illustrates the maximum relative twist of the three buildings shown in Figure 6 (Buildings A10, A28 and A36) as a function of the normalized period $T_{\mathrm{P}} / T_{1}$ for $\gamma=2.0$ and distinct values of $c_{\mathrm{H}}=2.0,2.9,3.8 \mathrm{~km} / \mathrm{s}$ and $\beta=170,270,560,1130 \mathrm{~m} / \mathrm{s}$. Each line style represents a certain wave apparent velocity, whereas the four shear wave velocities are not specified individually since their impact on the torsional response for a particular $c_{\mathrm{H}}$ value is insignificant. Figure 8 shows that the maximum relative twist increases as $c_{\mathrm{H}}$ decreases. This observation is consistent with findings reported in the literature indicating that a lower value of $c_{\mathrm{H}}$ would induce a larger torsional response (e.g. Luco and Sotiropoulos, 1980; Li et al., 1993; Aviles and Suarez, 2006) and that the maximum rotation of the ground about the vertical axis is inversely proportional to $c_{\mathrm{H}}$ (Newmark, 1969). More importantly, although the shear wave velocity $\beta$ (through the relative stiffness parameter $a_{1}$ ) and the angle of incidence $\Theta$ were found to be important parameters for the transfer function (see Section 2.4) and thus for the relative twist (see Section 4.1), Figure 8 suggests that it is actually the wave apparent velocity $c_{\mathrm{H}}$ that determines the relative torsional response of the superstructure. These numerical results are not surprising, since careful inspection of the mathematical formulation of the transfer function reveals that the foundation input twist $a^{*}$ depends on $\cos \Theta / \beta$, which is exactly the inverse of $c_{\mathrm{H}}$.

\subsection{Effect of Building Parameters}

In this section, the effect of building parameters on torsional response due to wave passage in the near-fault region is investigated. Figure 9 presents the maximum relative twist of all 40 buildings listed in Table 1 as a function of $T_{\mathrm{P}} / T_{1}$ for $\beta=170,270,560,1130 \mathrm{~m} / \mathrm{s}$ and $\gamma=2.0$, whereas $c_{\mathrm{H}}$ is selected as $2.0 \mathrm{~km} / \mathrm{s}$ to obtain the most critical response. Note that the effective range of $T_{\mathrm{P}} / T_{1}$ over which each 
response curve is plotted is different for each building because of its distinct torsional period $T_{1}$. Figure 9 shows that both the shape and amplitude of the response curves are remarkably similar to one another, especially as the shear wave velocity increases.

This trend is schematically explained in Figure 10 where Buildings A36 ( $\left.T_{1}=0.86 \mathrm{~s}\right)$ and A28 $\left(T_{1}=2.76 \mathrm{~s}\right)$ are excited by near-fault pulses with $T_{\mathrm{P}}$ values of $1.03 \mathrm{~s}$ and $3.31 \mathrm{~s}$, respectively. These pulse periods were selected so that $T_{\mathrm{P}} / T_{1}=1.2$ for both buildings. Without loss of generality, the shear wave velocity is considered to be equal to $270 \mathrm{~m} / \mathrm{s}$, whereas $\gamma$ is set equal to 2 . Figure 10a presents a direct comparison between the Fourier amplitude spectra of the relative twist $\left|\alpha_{\mathrm{r}}(\omega) \cdot D(\omega)\right|$ for Buildings A36 and A28. It can be seen that both buildings vibrate in their fundamental mode and that their Fourier amplitude spectra are of similar shape. As was discussed in Section 2.4 and shown in Figures 4d and 4e, the amplitude of the first peak response of the transfer function $\left|a \alpha_{\mathrm{r}} / u_{\mathrm{g} 0}\right|$ increases linearly with $a_{1}$ (or equivalently, in the case study presented in Figure 10 where $\beta$ is fixed, $\left|\alpha_{\mathrm{r}} / u_{\mathrm{g} 0}\right|$ increases linearly with $\left.\omega_{1}\right)$ in the range of $a_{1}<0.8$. For reference, the $a_{1}$ values for Buildings A36 and A28 are 0.41 and 0.24, respectively. On the other hand, the Fourier amplitude of the ground displacement decreases quadratically with $\omega_{\mathrm{P}}$ as was discussed in Section 3.3 and shown in Figure 5. As a consequence, for a fixed value of $\omega_{1} / \omega_{\mathrm{P}}$ (or equivalently $T_{\mathrm{P}} / T_{1}$ ), an increase in $\omega_{1}$ (e.g. from Building A28 to Building A36) leads to a linear decrease of the peak of the Fourier amplitude spectrum of the relative twist, as shown in Figure 10a. Figure 10b illustrates the same information, but now the frequency $\omega$ and the Fourier amplitude of the relative twist $\left|\alpha_{\mathrm{r}}(\omega) \cdot D(\omega)\right|$ for Building A28 have been normalized with respect to $k=$ $\omega_{1}^{A 36} / \omega_{1}^{A 28}=3.21$, yielding a normalized Fourier amplitude spectrum that is identical to the Fourier amplitude spectrum of Building A36. According to the time scaling property of the Fourier transform (e.g. Papoulis, 1962), the frequency responses of Buildings A36 and A28 shown in Figure 10a correspond to time signals of the same amplitude and waveform characteristics, but with a scaled time vector. Figure 10c shows the time histories of the relative twist for Buildings A36 and A28 confirming the time scaling property of the Fourier transform. Furthermore, Figure 10d shows that the Fourier amplitude spectra of Buildings A36 and A28 become identical, if properly normalized with $\omega_{1}$ (i.e. $\left|\alpha_{\mathrm{r}}\left(\omega / \omega_{1}\right) \cdot D\left(\omega / \omega_{1}\right)\right| \omega_{1}$ vs. $\left.\omega / \omega_{1}\right)$. It should be noted that the features shown in Figure 10 apply to all those buildings listed in Table 1 characterized by $a_{1}<0.8$. If $a_{1}>0.8$, relatively small differences in the amplitude of the maximum relative twist are observed.

On the other hand, the small variation in torsional response caused by different shear wave velocities (see Figure 9) confirms that local site condition have an insignificant effect on relative twist. This effect is even less pronounced for larger values of the shear wave velocity. This observation can be explained by considering that increased values of shear wave velocity would result in more sites within 
the range of $a_{1}<0.8$, thus satisfying the condition of the linearly increasing peak amplitude of the transfer function mentioned in the previous paragraph. Finally, the case study presented in Figure 10 indicates that building parameters such as height and radius have relatively insignificant effect on the torsional response, especially for stiff soil conditions, whereas the period ratio $T_{\mathrm{P}} / T_{1}$ is clearly the dominant parameter.

\section{Torsional Response due to Broadband Near-Fault Pulse-Like Ground Motions}

In this section, broadband near-fault pulse-like ground motions are simulated and the effects of wave passage on the torsional response of symmetric, elastic buildings subjected to these synthetic motions is investigated. The objective is twofold: (a) estimate the amplitude of the relative twist that buildings may experience under broadband near-fault pulse-like excitations, and (b) investigate the effectiveness of idealized pulse models to estimate the building torsional response.

\subsection{Synthesis of Broadband Near-Fault Pulse-Like Ground Motions}

Mavroeidis and Papageorgiou (2003) proposed a simplified methodology for generating broadband near-fault pulse-like motions adequate for engineering analysis and design. Based on this technique, the coherent (long-period) ground motion component is simulated using the mathematical model presented in Section 3.1, whereas the incoherent (high-frequency) seismic radiation is synthesized using the specific barrier model (SBM) (Papageorgiou and Aki, 1983a,b; Papageorgiou, 2003). This simplified methodology has been applied to both hypothetical and actual earthquakes (e.g. Mavroeidis and Papageorgiou, 2003; Halldorsson et al., 2011).

The SBM is a physical model of the seismic source that applies both to the "near-fault" and "farfield" regions, allowing for consistent ground motion simulations over the entire frequency range and for all distances of engineering interest. In the context of the SBM, the fault is visualized as an ensemble of non-overlapping circular subevents of equal diameter $2 \rho_{0}$ that cover a rectangular fault with length $L$ and width $W$ (Figure 11). As the rupture front sweeps the fault plane with a rupture velocity $V$, a local stress drop $\Delta \sigma_{\mathrm{L}}$ occurs on each subevent. The subevent rupture starts from its center and spreads radially outward with a constant spreading velocity until it is arrested by the barriers, denoted by the shaded area between the cracks in Figure 11. The SBM has been calibrated to shallow crustal earthquakes of three different tectonic regions: interplate, intraplate, and extensional regimes (Halldorsson and Papageorgiou 2005). Given an earthquake magnitude and the tectonic region, the interdependence of other source parameters on the local stress drop $\Delta \sigma_{\mathrm{L}}$ and the barrier interval $2 \rho_{0}$ allows the causative earthquake fault to be constructed. Since the site of interest is considered to be in the "near field" of the ruptured fault, it is necessary to simulate time histories for each individual subevent of the SBM, rather than for the entire 
seismic event as an aggregate of subevents. As explained by Halldorsson et al. (2011), the subevent time histories are subsequently summed up at the site, appropriately lagged in time accounting for the time it takes the sweeping rupture front to reach the subevent and for the travel time of the seismic radiation from the subevent to the site. The high-frequency time histories simulated in this manner account for the directivity effects that the fault geometry and rupture progression have on the high-frequency strong motion expected at the given site.

In what follows, broadband near-fault pulse-like motions for three hypothetical earthquakes of $M_{\mathrm{W}}$ 5.8, 6.4 and 7.0 are simulated, representing moderate, moderate-to-large and large seismic events, respectively. The causative fault is assumed to be a vertical strike-slip fault in an interplate region. Figure 11 illustrates the fault-station geometry considered herein for the high-frequency ground motion simulations using the SBM. The diameter of the subenvents $2 \rho_{0}$ is $2.1,4.1,8.2 \mathrm{~km}$ for $M_{\mathrm{W}} 5.8,6.4$ and 7.0, respectively. According to the calibration of the SBM for interplate regimes (Halldorsson and Papageorgiou, 2005), the total number of subevents that make up the SBM is typically 15. For consistency and simplicity in our simulations, the 15 subevents are arranged in a $5 \times 3$ pattern for all three earthquakes, even though this subevent arrangement may not necessarily be realistic for the $M_{\mathrm{W}} 7.0$ earthquake because of the implied fault width. The station is located in the forward direction with respect to the propagation of rupture and the site characterization is assumed to be NEHRP site class D. The parameters for the simulation of the long-period component using the mathematical model proposed by Mavroeidis and Papageorgiou (2003) are chosen as $A=100 \mathrm{~cm} / \mathrm{s}, \gamma=2.0$, and $v=90^{\circ}$. Based on Equation (15), the pulse period $T_{\mathrm{p}}$ is calculated as 1.0, 2.0 and $4.0 \mathrm{~s}$ for $M_{\mathrm{W}}$ 5.8, 6.4 and 7.0, respectively. Figure 12 illustrates the high-frequency, long-period and broadband time histories of ground acceleration, velocity and displacement generated at the site of interest for the three seismic events.

\subsection{Results and Discussion}

The computational procedure for estimating the torsional response due to the synthetic highfrequency, long-period and broadband ground motions shown in Figure 12 is similar to the one outlined and applied in Section 4, except that the Fourier transform of the ground displacement is now obtained using the Fast Fourier transform for frequencies up to $15 \mathrm{~Hz}$. Figure 13 presents the variation of the maximum relative twist as a function of $T_{1}$ for all 40 buildings listed in Table 1 due to the hypothetical earthquakes described in Section 5.1. It is assumed that $c_{\mathrm{H}}=2.0 \mathrm{~km} / \mathrm{s}$ and $\gamma=2.0$, whereas the pulse period $T_{\mathrm{P}}$ corresponding to each earthquake is indicated by a dotted vertical line. With reference to Figure 13, the following observations are made: 
- For all three earthquakes, the maximum relative twist due to the high-frequency component of ground motion varies within the range of $10^{-6}$ to $6 * 10^{-4} \mathrm{rad}$, and tends to increase with earthquake magnitude due to the increasing amplitude of the high-frequency motion.

- For the $M_{\mathrm{W}}$ 5.8, 6.4 and 7.0 earthquakes, the agreement between the values of maximum relative twist due to long-period and broadband ground motions is very good for $T_{1}>0.5 \mathrm{~s}, 1.0 \mathrm{~s}$ and $2.5 \mathrm{~s}$, respectively. For smaller values of $T_{1}$, the maximum relative twist due to the broadband motion is clearly controlled by the high-frequency component. It should also be noted that the maximum relative twist due to the broadband motion is consistently greater than that of the long-period or highfrequency component.

- The maximum relative twist of short-period buildings $\left(T_{1}<0.5 \mathrm{~s}\right)$ appears to be relatively small for all three earthquakes and is controlled by the high-frequency component of ground motion, thus implying that torsional response of short-period buildings due to wave passage is relatively insensitive to near-fault pulse-like motions.

- For both the long-period and broadband ground motions, the global peaks of the maximum relative twist are of comparable magnitude and occur for buildings whose torsional period $T_{1}$ is close to the pulse period $T_{\mathrm{P}}$ of the seismic excitation. This implies that torsional response at resonance is associated with near-fault pulse-like motions. In addition, the maximum relative twist at resonance exceeds $10^{-3} \mathrm{rad}$, a value that is consistent with the relative twist of a 13-story steel momentresisting frame building computed by Maison and Ventura (1991) and with the upper bound of rotations in structures reported by Trifunac (2009).

It should be noted that for symmetric buildings, torsional response may also be caused by ground motion incoherence (associated with the high-frequency component of the near-fault ground motions), in addition to the wave passage effects considered herein. Therefore, the actual maximum relative twist of symmetric buildings could potentially be greater than the values obtained in the present study. Moreover, nonlinear soil response, ground failure, and soil liquefaction may induce additional transient and permanent rotations on ground surface near faults, which in turn may further affect the building torsional response (Trifunac, 2009).

\section{Conclusions}

The effects of wave passage on the torsional response of symmetric, elastic buildings subjected to near-fault pulse-like ground motions were investigated by considering soil-structure interaction effects and realistic configurations of buildings and soil conditions. The following conclusions are drawn: 
- Results of parametric analysis have shown that (a) the relative stiffness parameter $a_{1}$, the angle of incidence $\Theta$, the ratio of moments of inertia $I_{\mathrm{b}} / I_{\mathrm{s}}$, and the normalized frequency $\omega / \omega_{1}$ affect the amplitude of the transfer function of the relative twist, and (b) the pulse period $T_{\mathrm{P}}$ is the dominant parameter of the Fourier amplitude spectrum of ground displacement, whereas parameters $\gamma$ and $A$ contribute to its variability to a lesser extent.

- The peak value of the maximum relative twist is attained when the pulse period $T_{\mathrm{P}}$ of the ground excitation approaches the torsional period $T_{1}$ of the building, and increases by a factor of $\sim 2$ as $\gamma$ increases from 1 to 3 . In addition, the maximum relative twist strongly depends on the wave apparent velocity $c_{\mathrm{H}}$, rather than the local site conditions. Finally, building parameters such as height and radius have relatively insignificant effect on the relative twist, especially for stiff soil conditions.

- The maximum relative twist of short-period buildings appears to be relatively small and is controlled by the high-frequency component of ground motion, thus implying that torsional response of shortperiod buildings due to wave passage is relatively insensitive to near-fault pulse-like motions. The maximum relative twist at resonance is controlled by the long-period component of ground motion and exceeds $10^{-3} \mathrm{rad}$, a value that is consistent with the upper bound of rotations in structures reported in the literature.

As stated by Jennings (1997), simplified structural models can be useful in assessing the potential earthquake response of buildings when their detailed properties are not known and in estimating the demands placed on buildings subjected to strong ground motions under the assumption that the building response, although nonlinear, is describable by linear models with appropriate period and equivalent damping. This assumption implies that structural yielding is not excessive and is well distributed over the structure. In addition, simplified structural models have the potential to facilitate the extensive parametric analysis that is frequently required to identify the parameters of the seismic excitation and soilfoundation-structure system that control structural response. Nevertheless, it should be noted that approaches based on simplified structural models are not intended to replace standard practices in the final stages of the design of buildings.

\section{Acknowledgements}

George P. Mavroeidis and Yenan Cao would like to acknowledge financial support provided by the National Science Foundation under Grant No. CMMI-1360734. 


\section{References}

Anagnostopoulos, S. A., M. T. Kyrkos, and K. G. Stathopoulos (2015). Earthquake induced torsion in buildings: Critical review and state of the art, Earthquakes and Structures 8, 305-377.

ASCE (2010). Minimum Design Loads for Buildings and Other Structures: ASCE Standard 7-10, American Society of Civil Engineers, Reston, VA.

Aviles, J., and M. Suarez (2006). Natural and accidental torsion in one-storey structures on elastic foundation under non-vertically incident SH-waves, Earthquake Engineering and Structural Dynamics 35, 829-850.

Bernal, D., M. Dohler, S. Mozaffari Kojidi, K. Kwan, and Y. Liu (2015). First mode damping ratios for buildings, Earthquake Spectra 31, 367-381.

Bouchon, M., and K. Aki (1982). Strain, tilt, and rotation associated with strong ground motion in the vicinity of earthquake faults, Bulletin of the Seismological Society of America 72, 1717-1738.

BSSC (2004). NEHRP Recommended Provisions for Seismic Regulations for New Buildings and Other Structures, 2003 edition, Federal Emergency Management Agency, Washington, DC.

Cork, T. G., J. H. Kim, G. P. Mavroeidis, J. K. Kim, B. Halldorsson, and A. S. Papageorgiou (2016). Effects of tectonic regime and soil conditions on the pulse period of near-fault ground motions, Soil Dynamics and Earthquake Engineering 80, 102-118.

CTBUH (1995). Structural Systems for Tall Buildings, Council on Tall Buildings and Urban Habitat, McGraw-Hill, New York, NY.

De la Llera, J. C., and A. K. Chopra (1994). Accidental torsion in buildings due to base rotational excitation, Earthquake Engineering and Structural Dynamics 23, 1003-1021.

Gicev, V., M. D. Trifunac, and N. Orbovi (2015). Translation, torsion, and wave excitation of a building during soilstructure interaction excited by an earthquake SH pulse, Soil Dynamics and Earthquake Engineering 77, 391-401.

Halldorsson, B., G. P. Mavroeidis, and A. S. Papageorgiou (2011). Near-fault and far-field strong ground-motion simulation for earthquake engineering applications using the specific barrier model, Journal of Structural Engineering-ASCE 137, 433-444.

Halldorsson, B, and A. S. Papageorgiou (2005). Calibration of the specific barrier model to earthquakes of different tectonic regions, Bulletin of the Seismological Society of America 95, 1276-1300.

Heredia-Zavoni, E., and F. Barranco (1996). Torsion in symmetric structures due to ground-motion spatial variation, Journal of Engineering Mechanics-ASCE 122, 834-843.

Holtz, R. D., W. D. Kovacs, and T. C. Sheahan (2011). An Introduction to Geotechnical Engineering, $2^{\text {nd }}$ Edition, Prentice Hall, Upper Saddle River, NJ.

Hubbard, D. T., and G. P. Mavroeidis (2011). Damping coefficients for near-fault ground motion response spectra, Soil Dynamics and Earthquake Engineering 31, 401-417.

Jennings, P. C. (1997). Earthquake response of tall regular buildings, Report No. EERL 97-01, California Institute of Technology, Pasadena, CA. 
Juarez, M., and J. Aviles (2008). Effective eccentricity due to the effects of structural asymmetry and wave passage, Engineering Structures 30, 831-844.

Kham, M., J.-F. Semblat, P.-Y. Bard, and P. Dangla (2006). Seismic site-city interaction: Main governing phenomena through simplified numerical models, Bulletin of the Seismological Society of America 96, 19341951.

Li, B., F. G. A. Al-Bermani, and S. Kitipornchai (1993). Maximum response of asymmetric structures subject to a multicomponent earthquake, Earthquake Engineering and Structural Dynamics 22, 1047-1066.

Luco, J. (1976a). Torsional response of structures to obliquely incident seismic SH waves, Earthquake Engineering and Structural Dynamics 4, 207-219.

Luco, J. (1976b). Torsional response of structures for SH waves: the case of hemispherical foundations, Bulletin of the Seismological Society of America 66, 109-123.

Luco, J., and A. Mita (1987). Response of circular foundation to spatially random ground motion, Journal of Engineering Mechanics-ASCE 113, 1-15.

Luco, J. E., and D. A. Sotiropoulos (1980). Local characterization of free-field ground motion and effects of wave passage, Bulletin of the Seismological Society of America 70, 2229-2244.

Luco, J., and H. Wong (1982). Response of structures to nonvertically incident seismic waves, Bulletin of the Seismological Society of America 72, 275-302.

Luco, J., and H. Wong (1986). Response of a rigid foundation to a spatially random ground motion, Earthquake Engineering and Structural Dynamics 14, 891-908.

Maison, B. F., and C. E. Ventura (1991). Dynamic analysis of thirteen-story building, Journal of Structural Engineering-ASCE 117, 3783-3803.

Mavroeidis, G. P., and A. S. Papageorgiou (2003). A mathematical representation of near-fault ground motions, Bulletin of the Seismological Society of America 93, 1099-1131.

Mavroeidis, G. P., and A. S. Papageorgiou (2010). Effect of fault rupture characteristics on near-fault strong ground motions, Bulletin of the Seismological Society of America 100, 37-58.

Mavroeidis, G. P., G. Dong, and A. S. Papageorgiou (2004). Near-fault ground motions, and the response of elastic and inelastic single-degree-of-freedom (SDOF) systems, Earthquake Engineering and Structural Dynamics 33, 1023-1049.

Meza-Fajardo, K. C. (2004). Torsional response of structures to impulsive near-fault ground motions, M.S. Thesis, State University of New York at Buffalo, Buffalo, NY.

Meza-Fajardo, K. C., and A. S. Papageorgiou (2004). Torsional response of structures to impulsive near-fault ground motions, presented at the $99^{\text {th }}$ Annual Meeting of the Seismological Society of America, Palm Springs, CA [Abstract in Seismological Research Letters 75, 267].

Newmark, N. M. (1969). Torsion in symmetrical buildings, in Proceedings of the Fourth World Conference on Earthquake Engineering, Santiago, Chile 3, 19-32.

O'Rourke, M. J., M. C. Bloom, and R. Dobry (1982). Apparent propagation velocity of body waves, Earthquake Engineering and Structural Dynamics 10, 283-294. 
Papageorgiou, A. S. (2003). The barrier model and strong ground motion, Pure and Applied Geophysics 160, 603634.

Papageorgiou, A. S., and K. Aki (1983a). A specific barrier model for the quantitative description of inhomogeneous faulting and the prediction of strong ground motion. I. Description of the model, Bulletin of the Seismological Society of America 73, 693-722.

Papageorgiou, A. S., and K. Aki (1983b). A specific barrier model for the quantitative description of inhomogeneous faulting and the prediction of strong ground motion. Part II. Applications of the model, Bulletin of the Seismological Society of America 73, 953-978.

Papoulis, A. (1962). The Fourier Integral and Its Applications, McGraw-Hill, NY.

PEER/ATC (2010). Modeling and acceptance criteria for seismic design and analysis of tall buildings, Report No. PEER/ATC-72-1, Applied Technology Council and Pacific Earthquake Engineering Research Center, Redwood City, CA.

Saouma, V. E. (2004). Lecture Notes in Structural Engineering: Analysis and Design, Department of Civil, Environmental, and Architectural Engineering, University of Colorado, Boulder, CO.

Satake, N., K. Suda, T. Arakawa, A. Sasaki, and Y. Tamura (2003). Damping evaluation using full-scale data of buildings in Japan, Journal of Structural Engineering-ASCE 129, 470-477.

Stewart, J. P., R. B. Seed, and G. L. Fenves (1998). Empirical evaluation of inertial soil-structure interaction effects, Report No. PEER-98/07, Pacific Earthquake Engineering Research Center, Berkeley, CA.

Stewart, J. P., R. B. Seed, and G. L. Fenves (1999). Seismic soil-structure interaction in buildings. II: Empirical findings, Journal of Geotechnical and Geoenvironmental Engineering-ASCE 125, 38-48.

Trifunac, M. (2009). Review: Rotations in structural response, Bulletin of the Seismological Society of America 99, 968-979.

Tsogka, C., and A. Wirgin (2003). Simulation of seismic response in an idealized city, Soil Dynamics and Earthquake Engineering 23, 391-402.

Veletsos, A. S., and J. W. Meek (1974). Dynamic behavior of building-foundation systems, Earthquake Engineering and Structural Dynamics 3, 121-138.

Veletsos, A. S., and A. M. Prasad (1989). Seismic interaction of structures and soils: stochastic approach, Journal of Structural Engineering-ASCE 115, 935-956.

Zhang, J., and Y. Tang (2008). Dimensional analysis of linear soil-foundation-structure system subjected to nearfault ground motions, in Proceedings of the 2008 Structures Congress, Vancouver, Canada. 


\section{LIST OF TABLES}

TABLE

1
TITLE

Buildings considered in present study (modified after Stewart et al., 1998, 1999). 
Table 1. Buildings considered in present study (modified after Stewart et al., 1998, 1999)

\begin{tabular}{|c|c|c|c|c|c|c|c|}
\hline $\begin{array}{c}\text { Site } \\
\text { index }^{a}\end{array}$ & Building & $\begin{array}{l}\text { Structural } \\
\text { system }^{\mathrm{b}}\end{array}$ & $\begin{array}{l}\text { No. } \\
\text { stories }\end{array}$ & $\operatorname{Height}^{\mathrm{c}}(\mathrm{m})$ & $\begin{array}{l}\text { Foundation } \\
\text { radius }^{\mathrm{d}}(\mathrm{m})\end{array}$ & $\begin{array}{l}\text { Fixed-base } \\
\text { fundamental } \\
\text { translational } \\
\text { period (s) }\end{array}$ & $\begin{array}{l}\text { Soil shear } \\
\text { wave } \\
\text { velocity } \\
(\mathrm{m} / \mathrm{s})\end{array}$ \\
\hline \multicolumn{8}{|c|}{ "A" Sites } \\
\hline 1 & Eureka Silvercrest Apts. & SW & 5 & 13.5 & 17.4 & 0.15 & 213.7 \\
\hline 4 & Emeryville Pacific Pk. Plaza & $\mathrm{CF}$ & 31 & 94.9 & 26.5 & 2.45 & 136.6 \\
\hline 5 & Hayward City Hall & DWF & 11 & 36.6 & 20.1 & 1.11 & 673.6 \\
\hline 8 & Piedmont Jr. High School & SW & 3 & 10.9 & 15.8 & 0.16 & 554.7 \\
\hline 10 & Richmond City Hall & DWF & 3 & 14.4 & 22.9 & 0.28 & 234.1 \\
\hline 11 & San Jose 3-St. Offc. Bldg. & SF & 3 & 15.2 & 26.2 & 0.67 & 805.3 \\
\hline 12 & El Centro Imp. Co. Ser. Bldg. & DWF & 6 & 23.5 & 18.6 & 0.50 & 141.4 \\
\hline 13 & Indio 4-St. Gov’t Offc. Bldg. & DWF & 4 & 24.4 & 21.0 & 0.67 & 211.8 \\
\hline 14 & Lancaster 3-St. Offc. Bldg. & SW & 3 & 11.3 & 16.5 & 0.20 & 276.8 \\
\hline 15 & Lancaster 5-St. Hospital & SF & 5 & 17.4 & 30.2 & 0.69 & 305.1 \\
\hline 17 & Loma Linda VA Hos. & SW & 4 & 21.8 & 75.0 & 0.25 & 431.3 \\
\hline 20 & Long Beach VA Hospital & SW & 11 & 42.7 & 25.6 & 0.51 & 348.4 \\
\hline 23 & LA 6-St. Offc. Bldg. & SF & 5 & 24.4 & 6.5 & 0.82 & 192.0 \\
\hline 24 & LA 6-St. Pkg. Garage & SW & 6 & 17.4 & 48.5 & 0.51 & 265.2 \\
\hline 26 & LA 7-St. UCLA Bldg. & DWF & 7 & 28.7 & 10.1 & 0.63 & 167.0 \\
\hline 27 & LA 15-St. Offc. Bldg. & SF & 17 & 75.8 & 39.9 & 3.20 & 353.9 \\
\hline 28 & LA 19-St. Offc. Bldg. & SF & 19 & 95.8 & 28.0 & 3.45 & 298.7 \\
\hline 29 & LA Hollywood Storage Bldg. & $\mathrm{CF}$ & 14 & 41.8 & 18.0 & 1.77 & 283.5 \\
\hline 30 & LA Wadsworth VA Hospital & SF & 6 & 34.0 & 57.6 & 0.92 & 299.0 \\
\hline 31 & Newport Beach Hoag Hospital & SW & 11 & 40.9 & 18.6 & 0.70 & 307.5 \\
\hline 33 & Norwalk 12440 Imp. Hwy. & SF & 7 & 31.4 & 43.3 & 1.30 & 276.2 \\
\hline 34 & Palmdale 4-St. Hotel & SW & 4 & 10.5 & 21.0 & 0.12 & 480.1 \\
\hline 35 & Pomona 2-St. Bldg. & $\mathrm{CF}$ & 2 & 12.2 & 18.0 & 0.25 & 379.8 \\
\hline 36 & Pomona 6-St. Bldg. & $\mathrm{CF}$ & 6 & 23.1 & 15.2 & 1.07 & 362.1 \\
\hline 38 & San Bernardino 3-St. & SF & 3 & 12.6 & 23.8 & 0.52 & 269.1 \\
\hline 39 & San Bernardino 5-St. & SW & 5 & 22.6 & 29.0 & 0.65 & 375.8 \\
\hline 40 & San Bernardino Vanir Tower & SF & 9 & 32.2 & 16.8 & 2.01 & 258.5 \\
\hline 41 & San Bernardino Co. Govt Cntr & SF & 5 & 16.5 & 34.7 & 0.51 & 308.2 \\
\hline 44 & Sylmar Olive View Med. Cen & SW & 6 & 27.4 & 38.4 & 0.27 & 459.0 \\
\hline 45 & Ventura 12-St. Hotel & SW & 12 & 30.0 & 18.9 & 0.53 & 270.1 \\
\hline \multicolumn{8}{|c|}{ "B" Sites } \\
\hline 2 & San Bruno 9-St. Offc. Bldg. & SW & 9 & 28.7 & 21.9 & 0.97 & 279.2 \\
\hline 3 & San Fran. 47-St. Offc. Bldg. & SF & 47 & 180.3 & 26.2 & 5.03 & 145.7 \\
\hline 5 & San Jose 10-St. Resid. Bldg. & SW & 10 & 26.6 & 19.8 & 0.29 & 234.1 \\
\hline 6 & San Jose 13-St. Gov't Offc. & SF & 12 & 47.5 & 25.3 & 2.13 & 221.0 \\
\hline 7 & Walnut Creek 10-St. Offc. & DWF & 10 & 38.8 & 9.8 & 0.66 & 428.2 \\
\hline 10 & LA 9-St. Offc. Bldg. & DWF & 9 & 38.8 & 15.2 & 1.25 & 267.6 \\
\hline 11 & LA 17-St. Resid. Bldg. & SW & 17 & 39.6 & 23.2 & 0.85 & 362.7 \\
\hline 12 & LA 32-St. Offc. Bldg. & DWF & 32 & 130.6 & 28.3 & 1.84 & 408.1 \\
\hline 13 & LA 54-St. Offc. Bldg. & SF & 54 & 180.3 & 29.3 & 5.70 & 401.4 \\
\hline 14 & Whittier 8-St. Hotel & SW & 8 & 20.9 & 19.5 & 0.49 & 256.6 \\
\hline
\end{tabular}




\section{LIST OF FIGURES}

FIGURE

TITLE

1 Model of the soil-foundation-structure system (modified after Luco, 1976a).

2 Histograms of dimensionless parameters $a_{1}$ and $I_{\mathrm{b}} / I_{\mathrm{s}}$ for all buildings listed in Table 1.

3 Modulus of normalized relative twist $\left|a \alpha_{\mathrm{r}} / u_{\mathrm{g} 0}\right|$ vs. normalized frequency $\omega / \omega_{1}$ for $a_{1}=0.2,0.7,1.2,2.2,3.2,5.0, \Theta=0^{\circ}, 40^{\circ}, 80^{\circ}$, and $I_{\mathrm{b}} / I_{\mathrm{s}}=0.1,0.8,1.7$. The soil density $\rho_{\mathrm{s}}$, the mass density of the superstructure $\rho_{\mathrm{b}}$, the foundation-to-superstructure mass ratio $m_{0} / m_{\mathrm{b}}$, and the hysteretic damping factor $\xi$ are equal to their average values (i.e. $\rho_{\mathrm{s}}=$ $1.95 \mathrm{Mg} / \mathrm{m}^{3}, \rho_{\mathrm{b}}=250 \mathrm{~kg} / \mathrm{m}^{3}, m_{0} / m_{\mathrm{b}}=0.2$, and $\left.\xi=4 \%\right)$.

4 (a) Amplitude of first peak response of $\left|a \alpha_{r} / u_{\mathrm{g} 0}\right|$ vs. $a_{1}$ and $\Theta$ for $I_{\mathrm{b}} / I_{\mathrm{s}}=0.1,0.8,1.7$. (b,c) Cross sections of Figure $4 \mathrm{a}$ for $a_{1}=1.5$ and 4.5. (d,e) Cross sections of Figure 4a for $\Theta=40^{\circ}$ and $80^{\circ}$.

$5 \quad$ Normalized Fourier amplitude spectrum of ground displacement vs. normalized frequency for $\gamma=1.0,1.5,2.0,3.0$.

6 Maximum relative twist between top and base of Buildings A10, A36 and A28 vs. $T_{\mathrm{P}} /$ $T_{1}$ for $\gamma=1.0,1.5,2.0,3.0$. The angle of incidence is considered to be $\Theta=40^{\circ}$ and $80^{\circ}$ for (a) and (b), respectively. The dotted vertical line specifies the lower limit of the effective range of $T_{\mathrm{P}} / T_{1}$ for each building.

7 (a) Same parametric analysis as in Figure 6a for Building A28, except that the response quantity of interest is the overall maximum relative twist between any point along the height of the building and its base. (b) Variation of maximum relative twist along height for Building A28 when $T_{\mathrm{P}} / T_{1}=0.2,1.0$ and 1.8 .

8 Maximum relative twist between top and base of Buildings A10, A36 and A28 vs. $T_{\mathrm{P}} /$ $T_{1}$ for $c_{\mathrm{H}}=2.0,2.9,3.8 \mathrm{~km} / \mathrm{s}$ and $\beta=170,270,560,1130 \mathrm{~m} / \mathrm{s}$. Parameter $\gamma$ is set equal to 2.0 .

9 Maximum relative twist between top and base of all 40 buildings listed in Table 1 vs. $T_{\mathrm{P}} / T_{1}$ for $\beta=170,270,560,1130 \mathrm{~m} / \mathrm{s}$. It is assumed that $c_{\mathrm{H}}=2.0 \mathrm{~km} / \mathrm{s}$ and $\gamma=2.0$.

10 Buildings A36 $\left(T_{1}=0.86 \mathrm{~s}\right)$ and A28 $\left(T_{1}=2.76 \mathrm{~s}\right)$ excited by near-fault pulses with $T_{\mathrm{P}}$ values of $1.03 \mathrm{~s}$ and $3.31 \mathrm{~s}$, respectively. Pulse periods were selected so that $T_{\mathrm{P}} / T_{1}=1.2$ for both buildings, whereas $\beta=270 \mathrm{~m} / \mathrm{s}$ and $\gamma=2.0$. (a) Fourier amplitude spectra of relative twist for Buildings A36 and A28. (b) Same as (a), except frequency and Fourier amplitude of relative twist for Building A28 are normalized with respect to $k=$ $\omega_{1}^{A 36} / \omega_{1}^{A 28}=3.21$. (c) Time histories of relative twist for Buildings A36 and A28. (d) Normalized Fourier amplitude spectra of relative twist for Buildings A36 and A28.

11 Schematic view of the fault-station geometry for the simulation of high-frequency ground motions using the Specific Barrier Model. The dashed lines show the rupture front at successive time instants.

12 Synthetic high-frequency (HF), long-period (LP) and broadband (BB) time histories of ground acceleration, velocity and displacement for three hypothetical earthquakes of $M_{\mathrm{W}}$ 5.8, 6.4 and 7.0 and the fault-station geometry shown in Figure 11.

13 Maximum relative twist between top and base of all 40 buildings listed in Table 1 as a function of $T_{1}$ due to the high-frequency (HF), long-period (LP) and broadband (BB) ground motions shown in Figure 12. The pulse period $T_{\mathrm{P}}$ for each earthquake is indicated by a dotted vertical line, whereas $c_{\mathrm{H}}=2.0 \mathrm{~km} / \mathrm{s}$ and $\gamma=2.0$. 


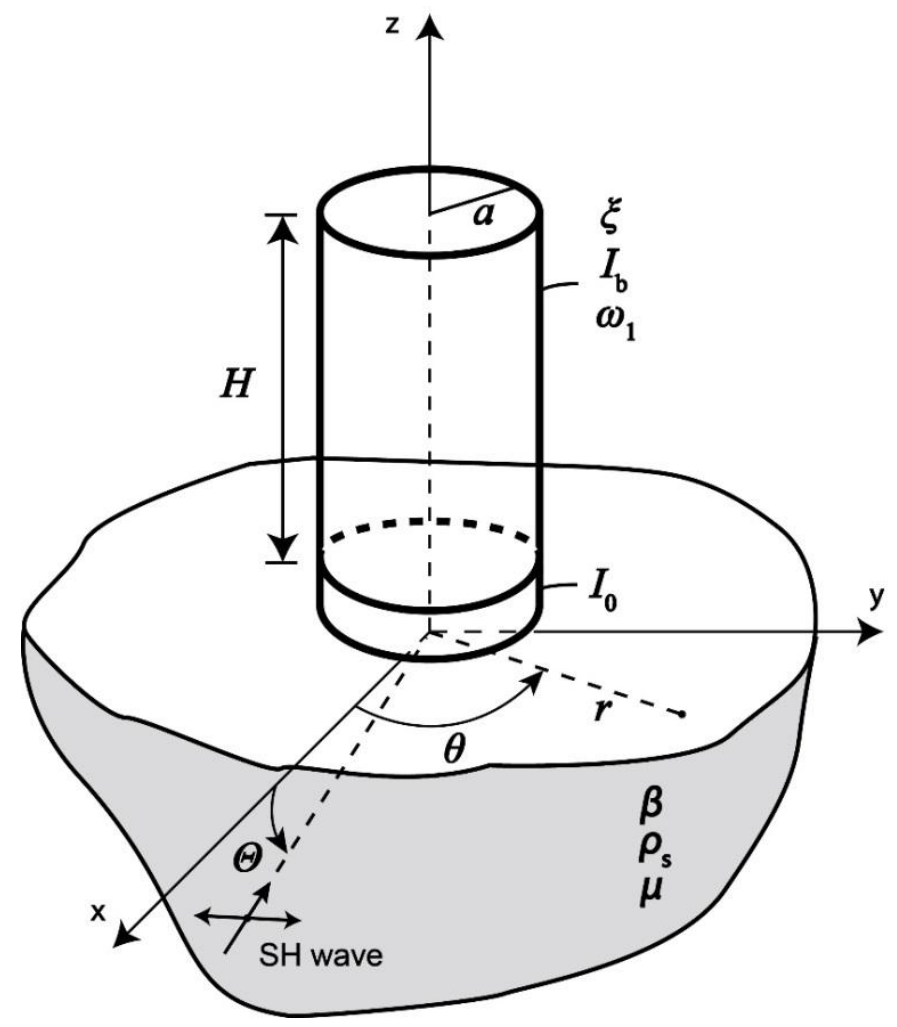

Fig. 1. Model of the soil-foundation-structure system (modified after Luco, 1976a). 

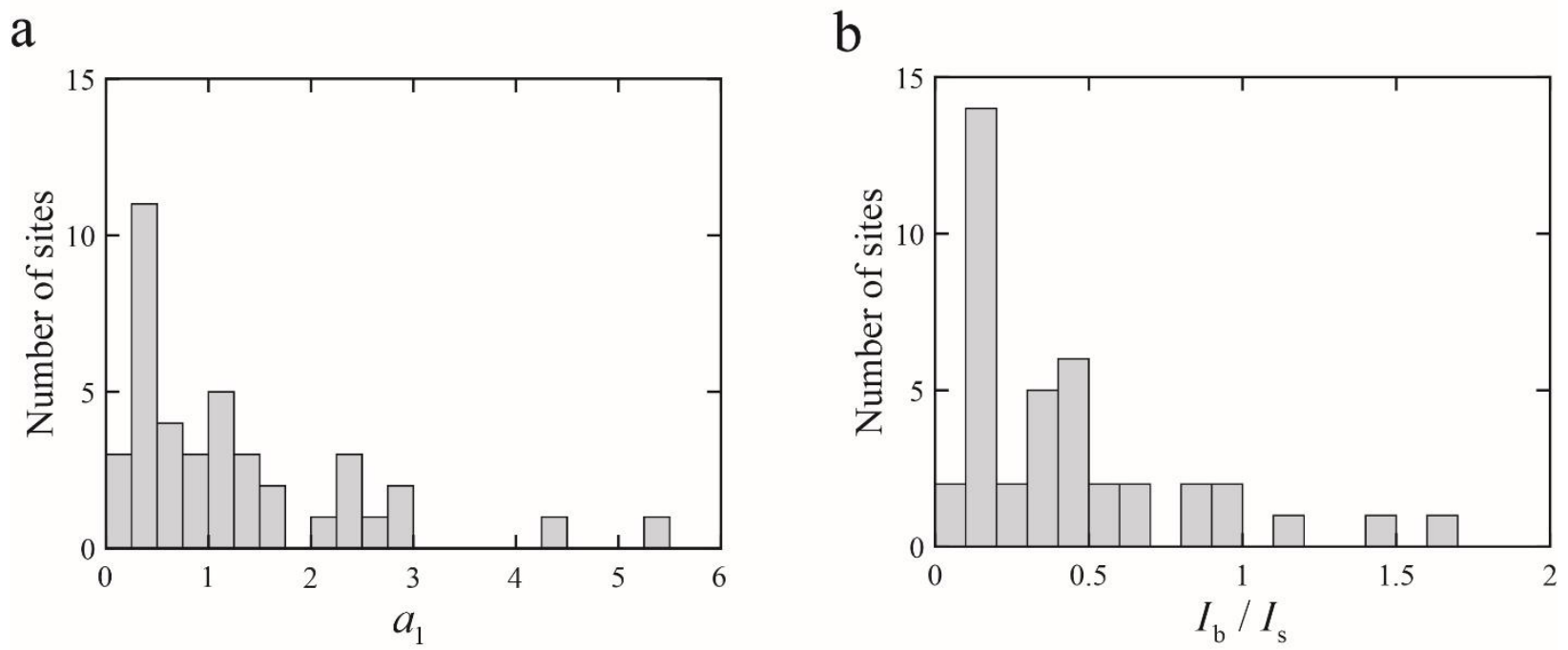

Fig. 2. Histograms of dimensionless parameters $a_{1}$ and $I_{\mathrm{b}} / I_{\mathrm{s}}$ for all buildings listed in Table 1 . 

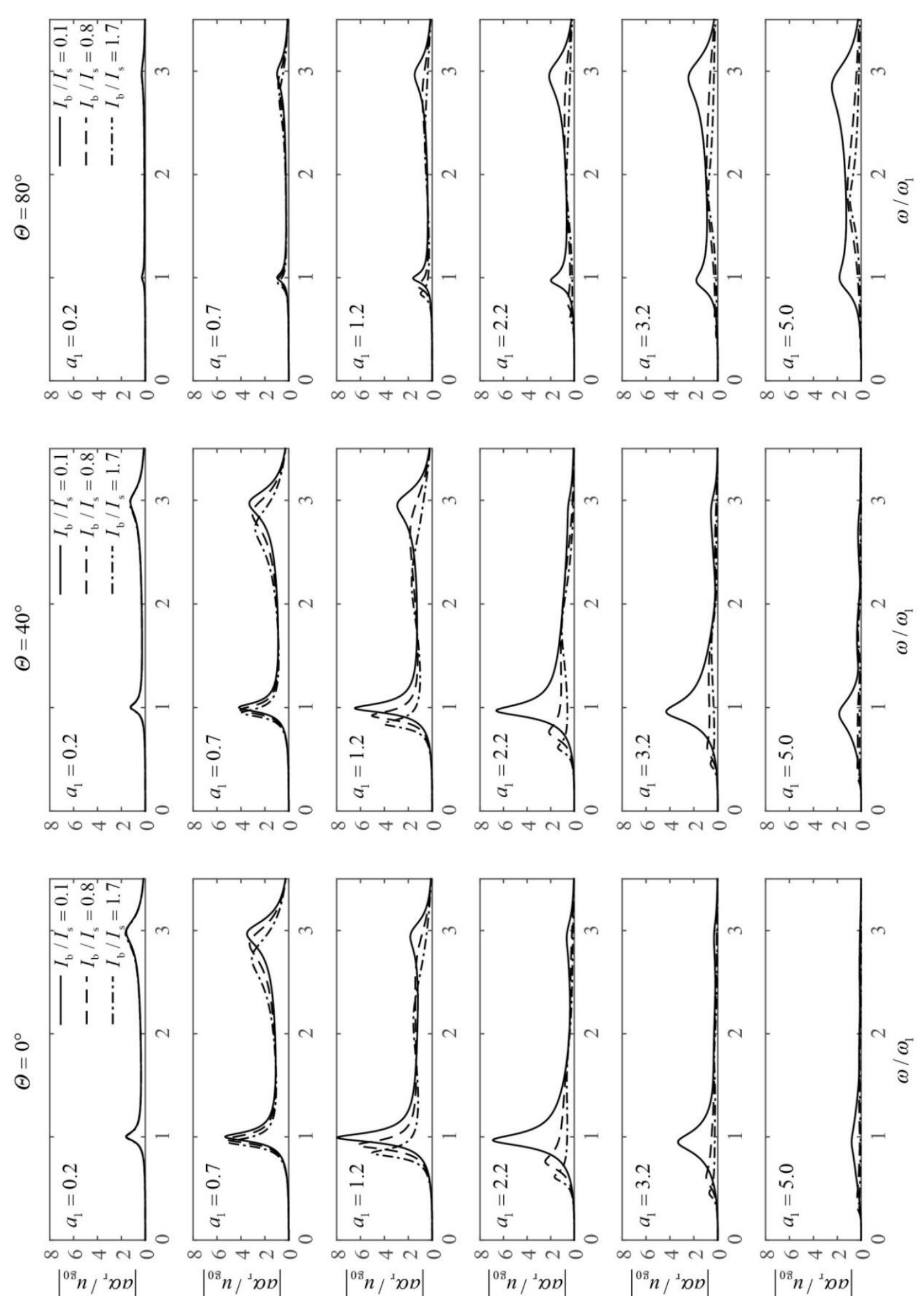

Fig. 3. Modulus of normalized relative twist $\left|a \alpha_{\mathrm{r}} / u_{\mathrm{g} 0}\right|$ vs. normalized frequency $\omega / \omega_{1}$ for $a_{1}=0.2,0.7,1.2,2.2,3.2,5.0, \Theta=0^{\circ}, 40^{\circ}, 80^{\circ}$, and $I_{\mathrm{b}} / I_{\mathrm{s}}=0.1,0.8,1.7$. The soil density $\rho_{\mathrm{s}}$, the mass density of the superstructure $\rho_{\mathrm{b}}$, the foundation-to-superstructure mass ratio $m_{0} / m_{\mathrm{b}}$, and the hysteretic damping factor $\xi$ are equal to their average values (i.e. $\rho_{\mathrm{s}}=1.95 \mathrm{Mg} / \mathrm{m}^{3}, \rho_{\mathrm{b}}=250 \mathrm{~kg} / \mathrm{m}^{3}, m_{0} / m_{\mathrm{b}}=0.2$, and $\xi=4 \%$ ). 

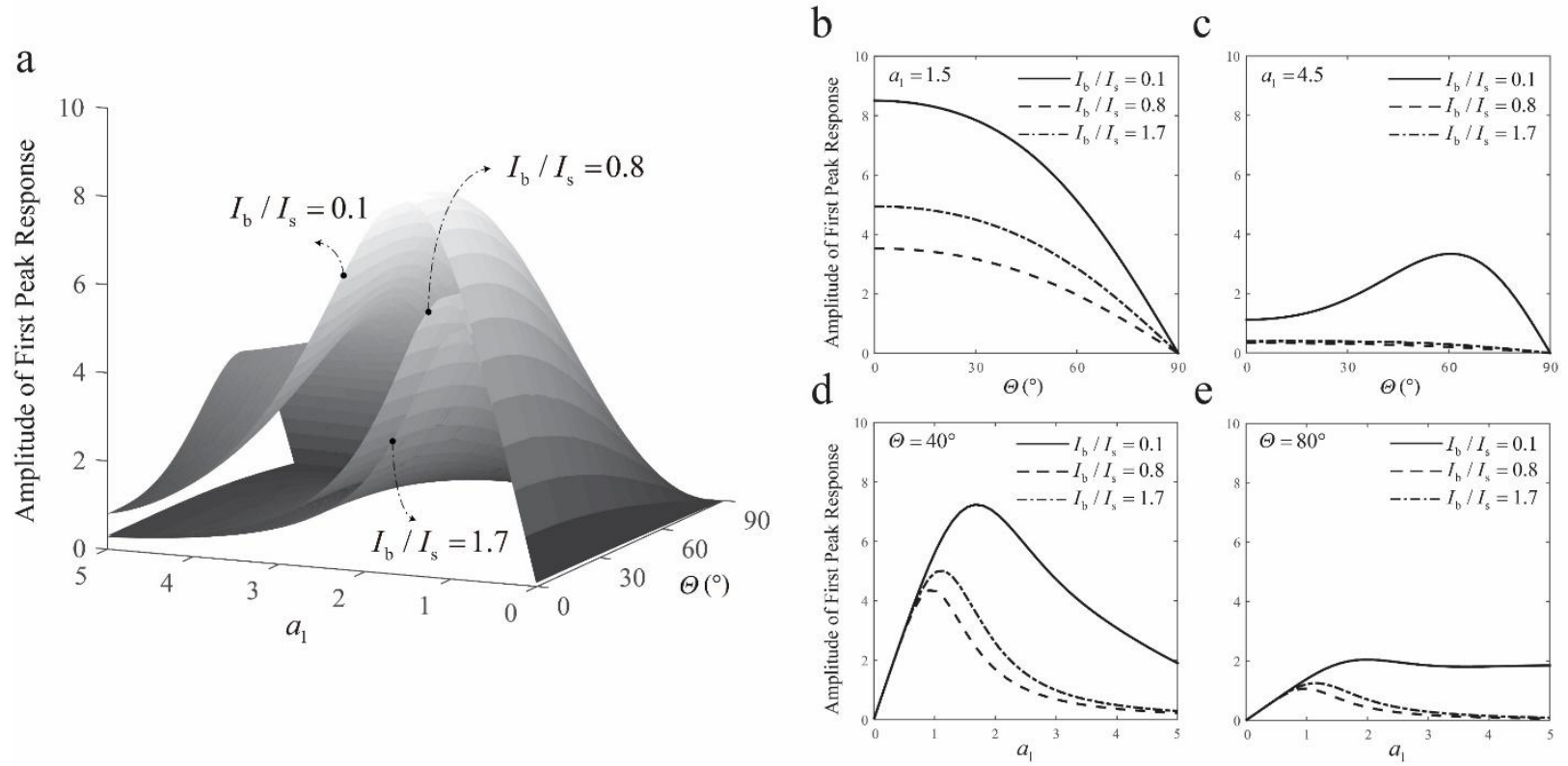

Fig. 4. (a) Amplitude of first peak response of $\left|a \alpha_{r} / u_{\mathrm{g} 0}\right|$ vs. $a_{1}$ and $\Theta$ for $I_{\mathrm{b}} / I_{\mathrm{s}}=0.1,0.8$, 1.7. (b,c) Cross sections of Figure 4a for $a_{1}=1.5$ and 4.5. (d,e) Cross sections of Figure $4 \mathrm{a}$ for $\Theta=40^{\circ}$ and $80^{\circ}$. 


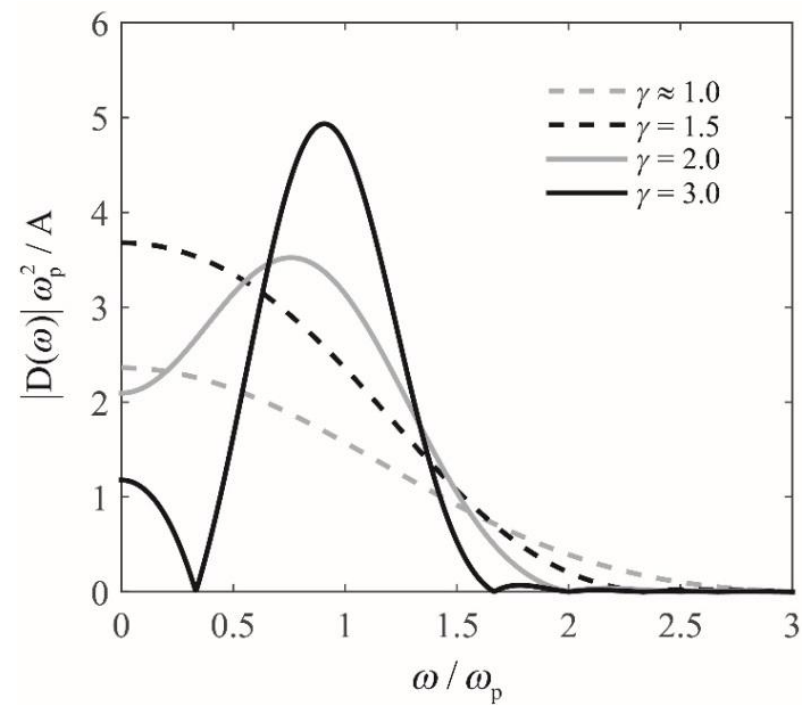

Fig. 5. Normalized Fourier amplitude spectrum of ground displacement vs. normalized frequency for $\gamma=$ 1.0, 1.5, 2.0, 3.0. 
a
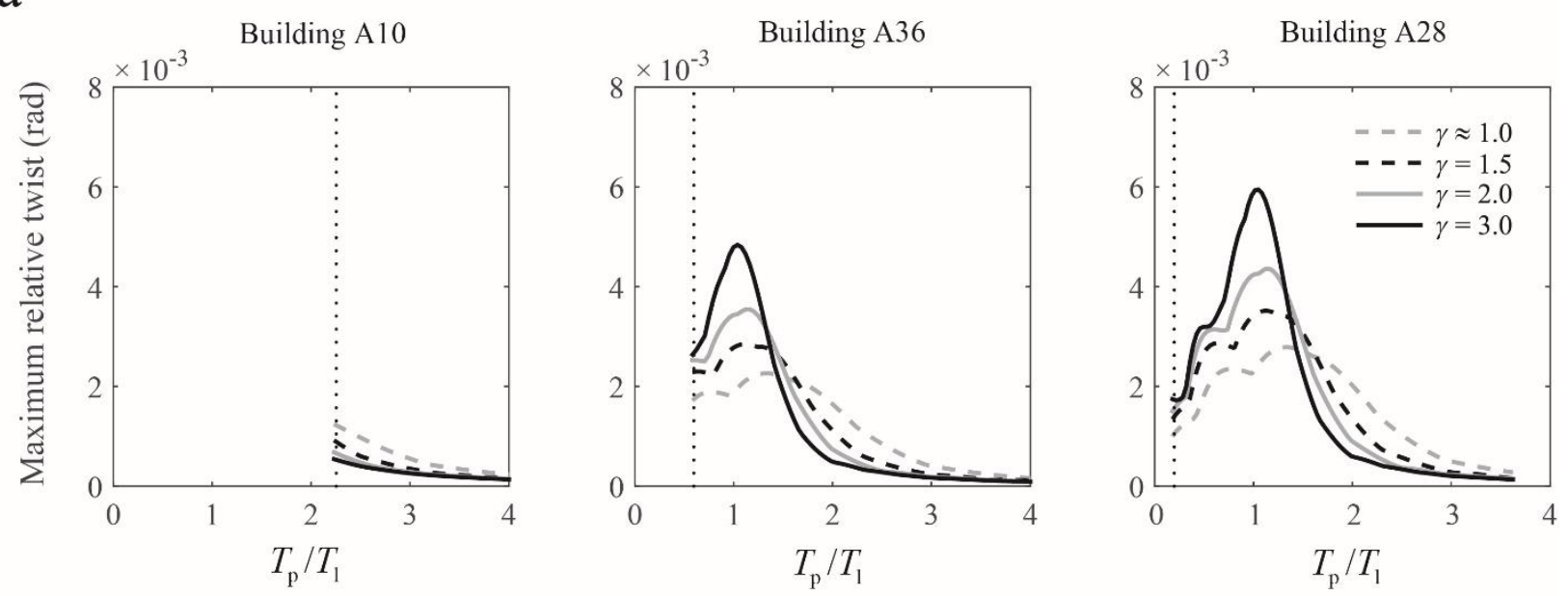

b
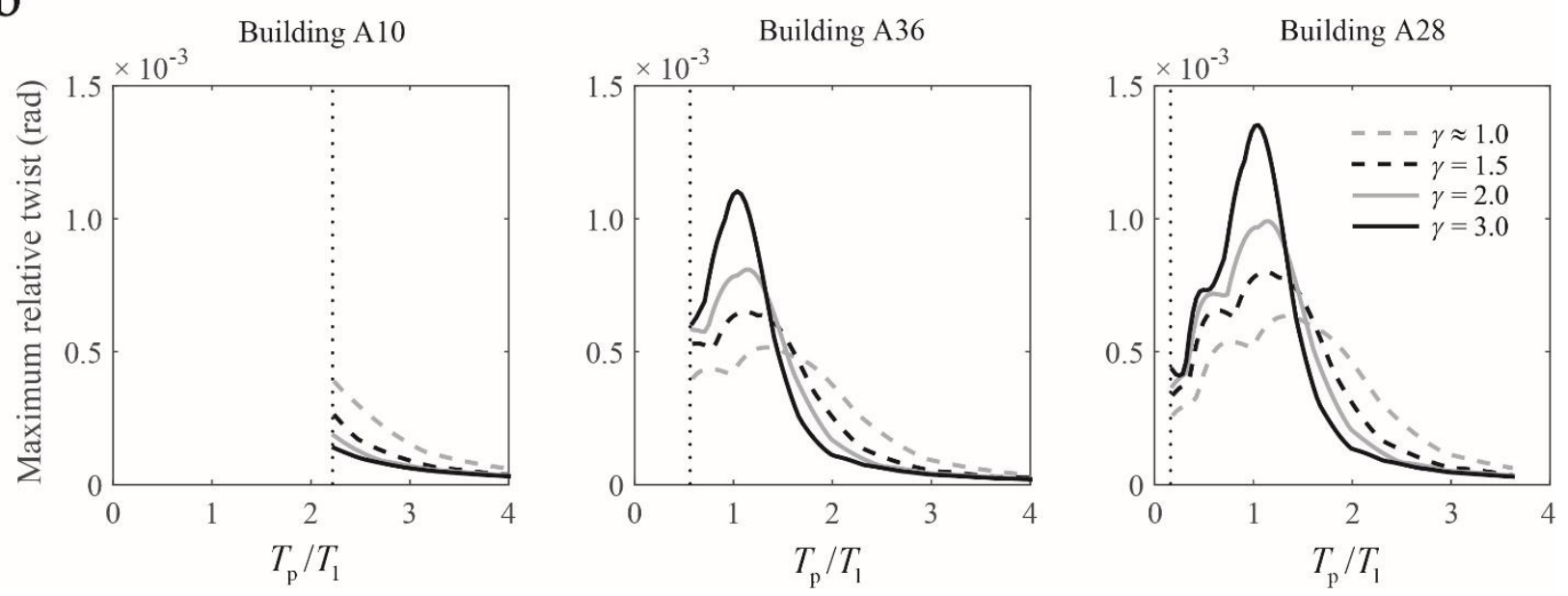

Fig. 6. Maximum relative twist between top and base of Buildings A10, A36 and A28 vs. $T_{\mathrm{P}} / T_{1}$ for $\gamma=$ $1.0,1.5,2.0,3.0$. The angle of incidence is considered to be $\Theta=40^{\circ}$ and $80^{\circ}$ for (a) and (b), respectively. The dotted vertical line specifies the lower limit of the effective range of $T_{\mathrm{P}} / T_{1}$ for each building. 
a

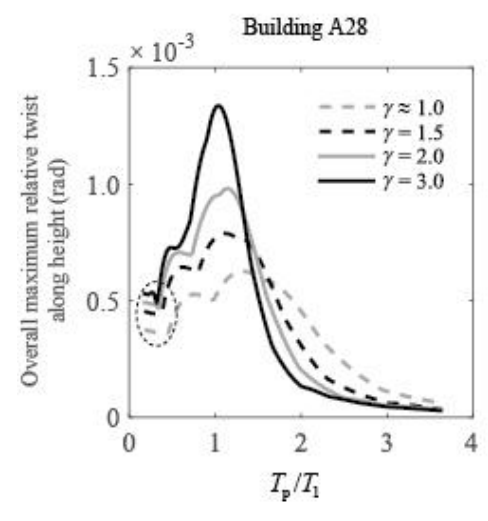

b

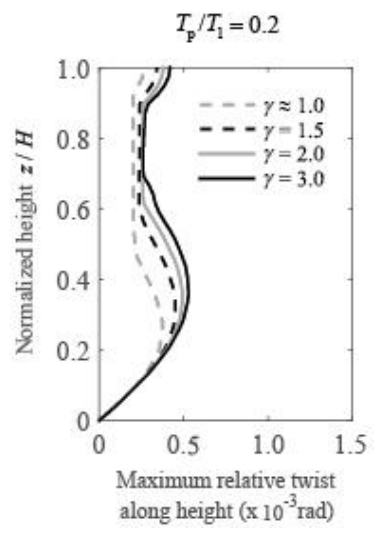

$T_{\mathrm{p}} / T_{1}=1.0$

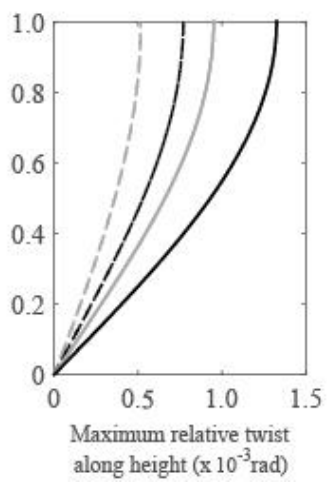

$T_{\mathrm{p}} / T_{1}=1.8$

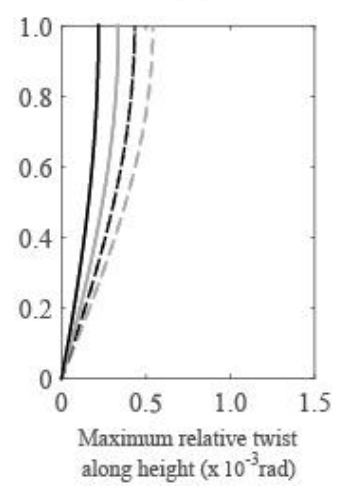

Fig. 7. (a) Same parametric analysis as in Figure 6a for Building A28, except that the response quantity of interest is the overall maximum relative twist between any point along the height of the building and its base. (b) Variation of maximum relative twist along height for Building A28 when $T_{\mathrm{P}} / T_{1}=0.2,1.0$ and 1.8. 

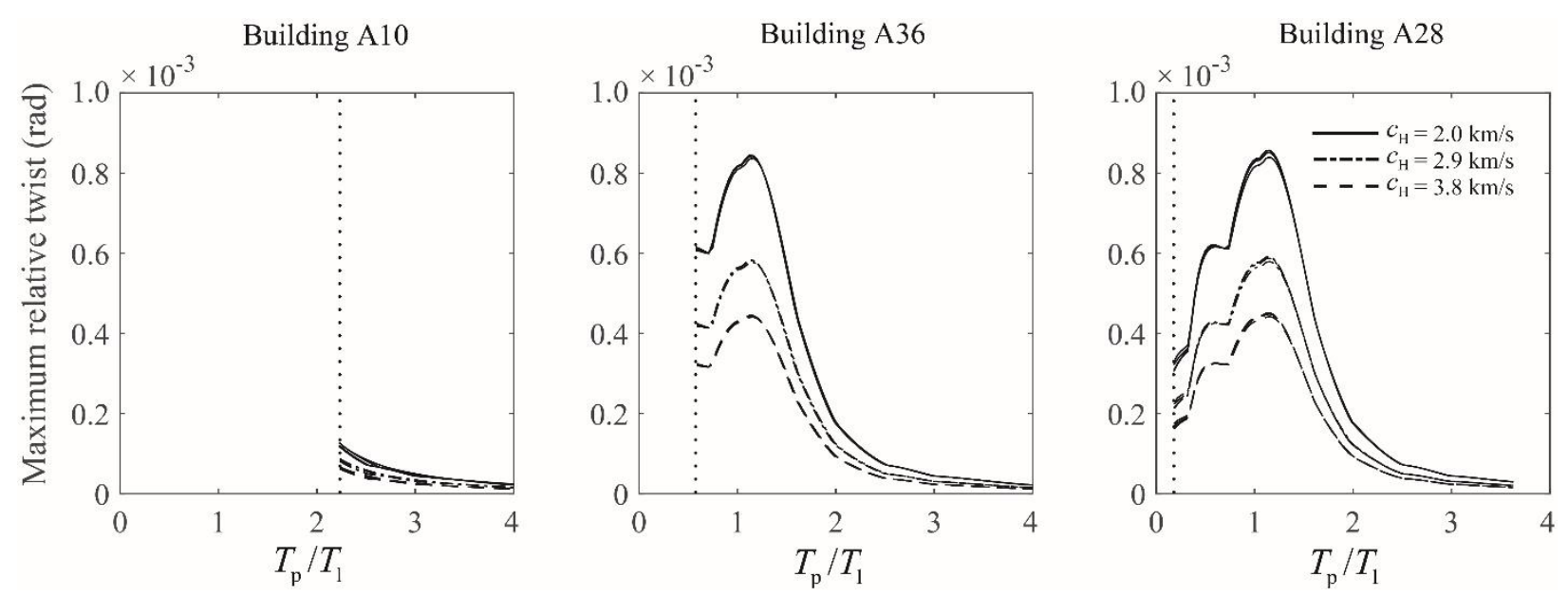

Fig. 8. Maximum relative twist between top and base of Buildings A10, A36 and A28 vs. $T_{\mathrm{P}} / T_{1}$ for $c_{\mathrm{H}}=$ 2.0, 2.9, $3.8 \mathrm{~km} / \mathrm{s}$ and $\beta=170,270,560,1130 \mathrm{~m} / \mathrm{s}$. Parameter $\gamma$ is set equal to 2.0. 

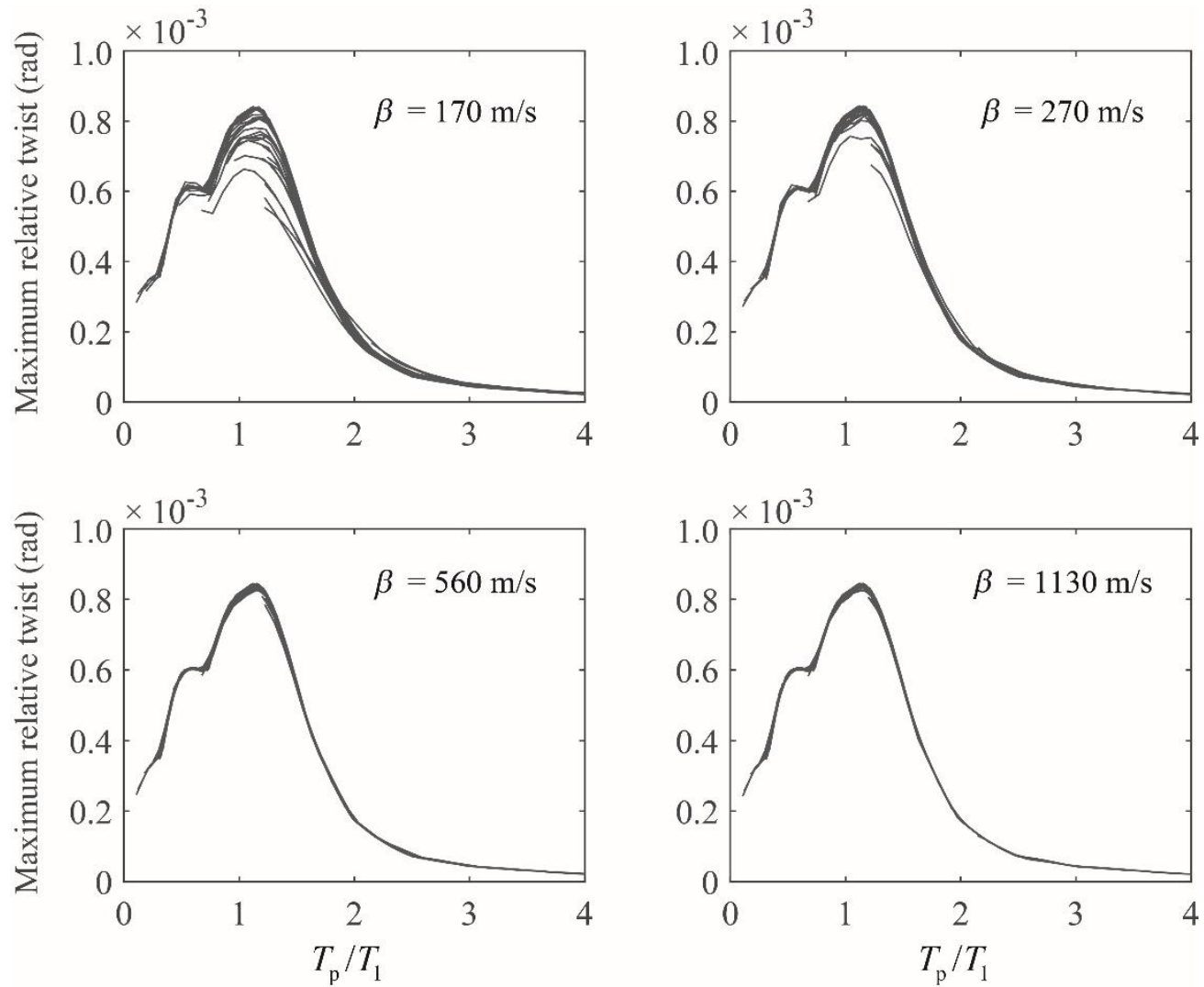

Fig. 9. Maximum relative twist between top and base of all 40 buildings listed in Table 1 vs. $T_{\mathrm{P}} / T_{1}$ for $\beta=$ $170,270,560,1130 \mathrm{~m} / \mathrm{s}$. It is assumed that $c_{\mathrm{H}}=2.0 \mathrm{~km} / \mathrm{s}$ and $\gamma=2.0$. 

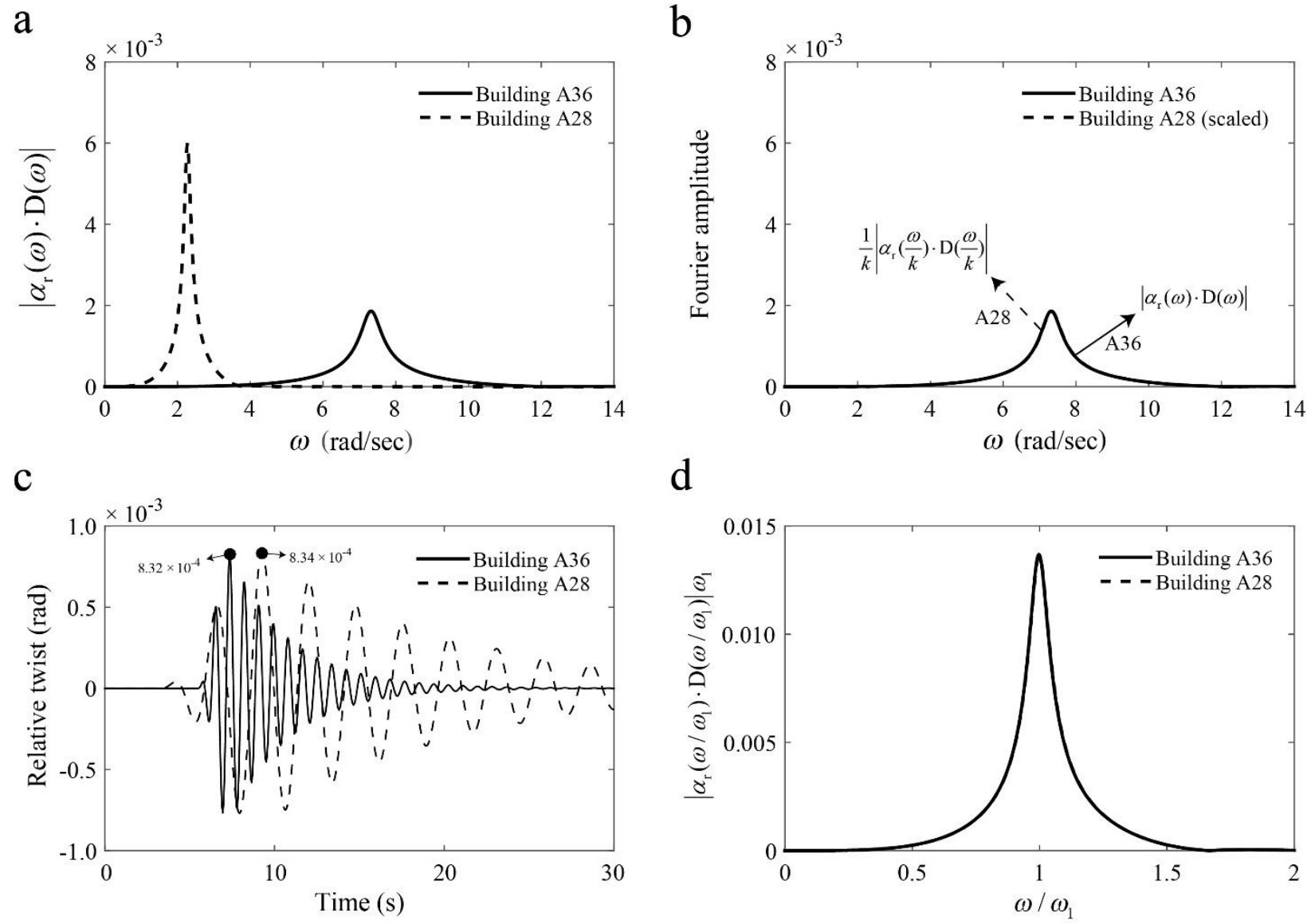

Fig. 10. Buildings A36 ( $\left.T_{1}=0.86 \mathrm{~s}\right)$ and A28 $\left(T_{1}=2.76 \mathrm{~s}\right)$ excited by near-fault pulses with $T_{\mathrm{P}}$ values of $1.03 \mathrm{~s}$ and $3.31 \mathrm{~s}$, respectively. Pulse periods were selected so that $T_{\mathrm{P}} / T_{1}=1.2$ for both buildings, whereas $\beta=270 \mathrm{~m} / \mathrm{s}$ and $\gamma=2.0$. (a) Fourier amplitude spectra of relative twist for Buildings A36 and A28. (b) Same as (a), except frequency and Fourier amplitude of relative twist for Building A28 are normalized with respect to $k=\omega_{1}^{A 36} /$ $\omega_{1}^{A 28}=3.21$. (c) Time histories of relative twist for Buildings A36 and A28. (d) Normalized Fourier amplitude spectra of relative twist for Buildings A36 and A28. 


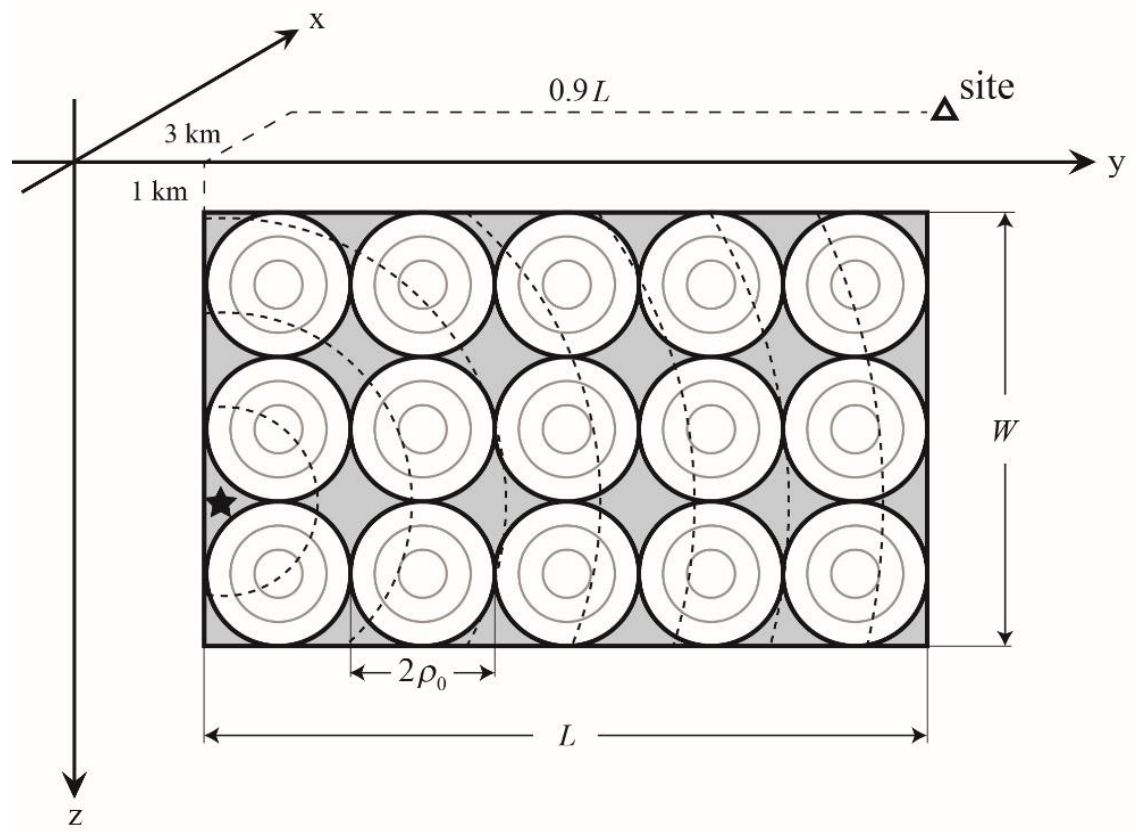

Fig. 11. Schematic view of the fault-station geometry for the simulation of high-frequency ground motions using the Specific Barrier Model. The dashed lines show the rupture front at successive time instants. 


$$
M_{\text {w }} 5.8
$$

Acceleration
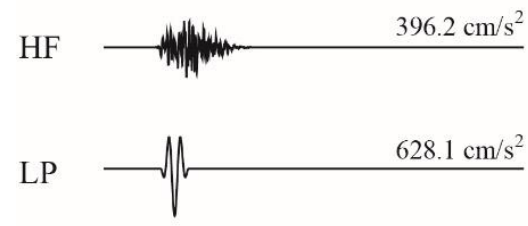

BB

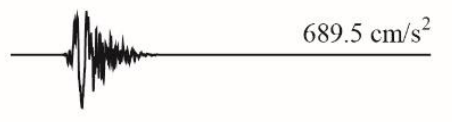

Velocity

$\mathrm{HF}$
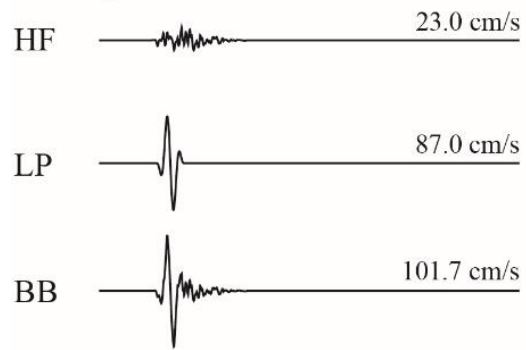

Displacement

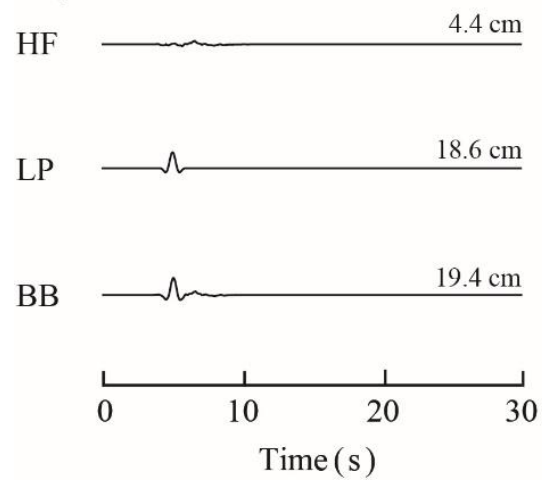

$M_{\mathrm{w}} 6.4$
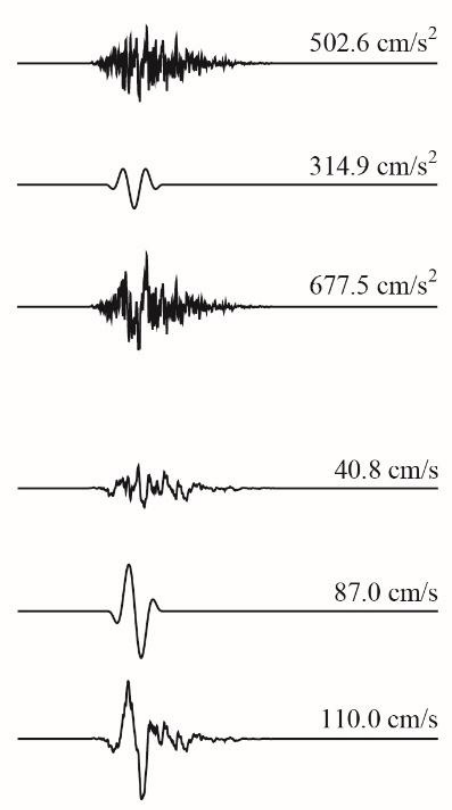

$7.6 \mathrm{~cm}$
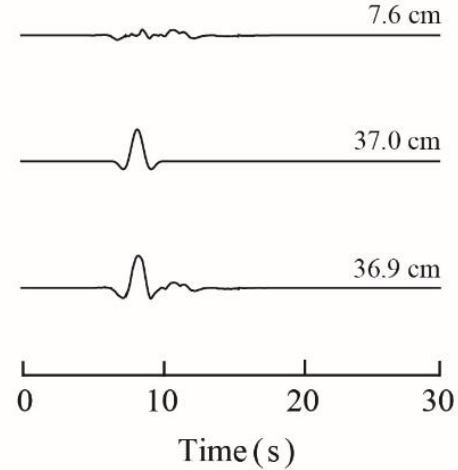

$M_{\mathrm{w}} 7.0$
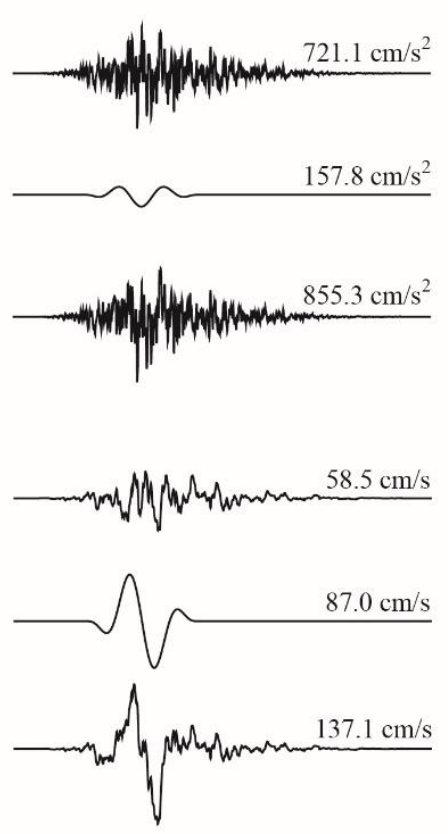

$18.6 \mathrm{~cm}$
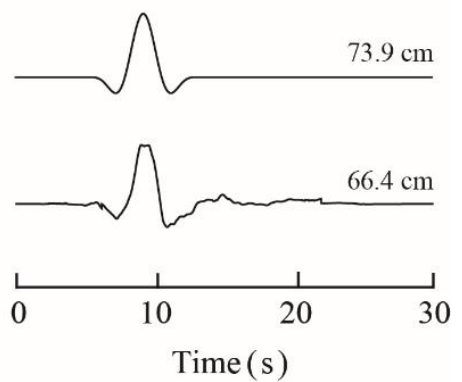

Fig. 12. Synthetic high-frequency (HF), long-period (LP) and broadband (BB) time histories of ground acceleration, velocity and displacement for three hypothetical earthquakes of $M_{\mathrm{W}} 5.8,6.4$ and 7.0 and the fault-station geometry shown in Figure 11. 

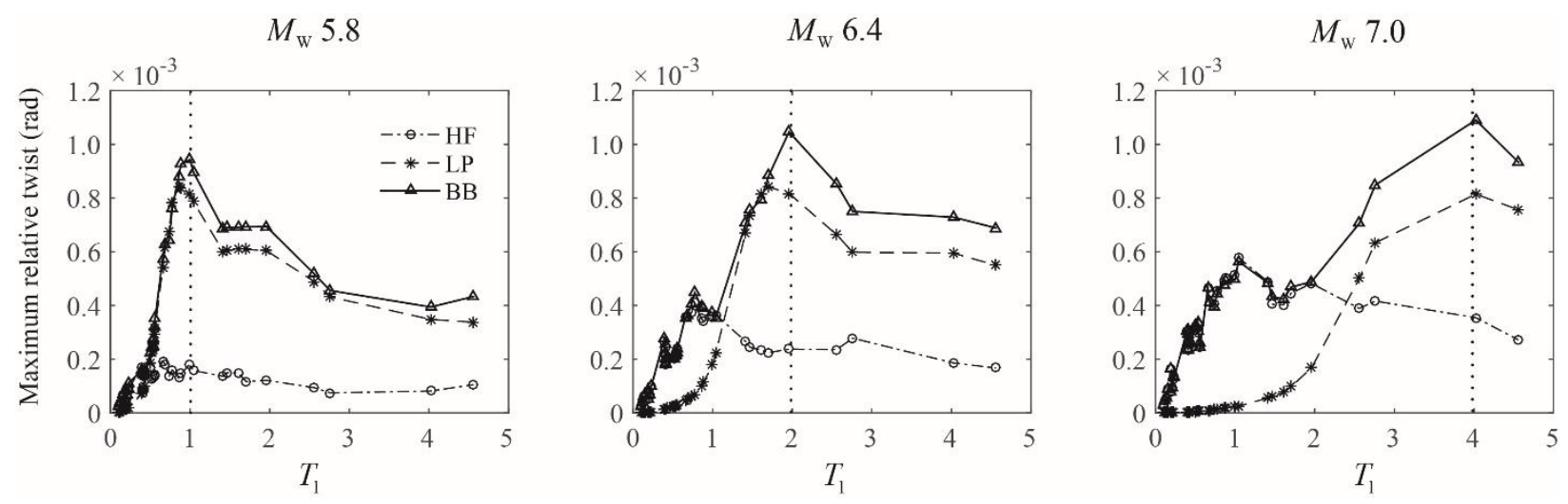

Fig. 13. Maximum relative twist between top and base of all 40 buildings listed in Table 1 as a function of $T_{1}$ due to the high-frequency (HF), long-period (LP) and broadband (BB) ground motions shown in Figure 12. The pulse period $T_{\mathrm{P}}$ for each earthquake is indicated by a dotted vertical line, whereas $c_{\mathrm{H}}=2.0 \mathrm{~km} / \mathrm{s}$ and $\gamma=2.0$. 